\title{
Monetary Rules, Determinacy and Limited Enforcement
}

\author{
Jean Barthélemy ${ }^{1}$ \& Eric Mengus ${ }^{2}$
}

\author{
November 2018, WP 700
}

\begin{abstract}
This paper investigates the ability of monetary policy rules to coordinate private agents' expectations when the enforcement of rules is limited. We show that limited enforcement precludes diverging inflation paths ensuring that nominal variables remain bounded in equilibrium. When applied to Taylor rules this makes the Taylor principle necessary and sufficient for price determinacy. However, limited enforcement also allows agents to rationally anticipate multiple policies and we show that, in general, there is no policy rule able to recoordinate any private agents' belief on that rule. We finally provide conditions under which such recoordination may take place.
\end{abstract}

Keywords: Policy Rules, Determinacy, Limited Enforcement.

JEL classification: E31; E52; E65

\footnotetext{
${ }^{1}$ Financial research dept, Banque de France. jean.barthelemy@,banque-france.fr;

${ }^{2}$ HEC Paris. mengus@,hec.fr;

We thank Marco Bassetto, John Cochrane, Stéphane Dupraz, Gaetano Gaballo, Klodiana Istrefi, Olivier Loisel, Eduardo Perez, Guillaume Plantin, Franck Portier, Xavier Ragot, Sergio Rebelo, Ricardo Reis and François Velde for helpful comments as well as seminar participants at Banque de France, Sciences Po, the 2017 Transaltantic Theory Workshop (Palaiseau), the 2017 T2M Conference (Lisbon) and the 11th Joint French Macro Workshop (Paris). All remaining errors are ours.
}

Working Papers reflect the opinions of the authors and do not necessarily express the views of the Banque de France. This document is available on publications.banque-france.fr/en 


\section{NON-TECHNICAL SUMMARY}

Governments and central banks are more and more relying on rules to enhance the efficiency of fiscal or monetary policies: committing to a rule both allows overcoming potential time inconsistency problems - ex ante desirable policies may be ex post suboptimal - and helps to better steer private sector expectations to desired economic outcomes, simply by making policy decisions more transparent and more predictable.

However, policymakers sometimes prefer to breach the rule, e.g., when the cost of adhering to the rule becomes larger than the cost of breaching the rule. Indeed, the enforcement of a policy rule is unlikely to be unlimited. But if rules can be breached, what can we really expect from a policymaker following a policy rule? Does the possibility to breach the rule completely delete the usefulness of rules and especially the ability of rules to guide private agents' expectations on a unique desired equilibrium - so called price determinacy?

In this paper, we investigate the ability of policy rules to coordinate private agents when the incentives to follow through on rules are limited. We characterize the set of equilibria produced by policy rules under limited enforcement and we provide conditions under which the expectation of a policy rule ensures price determinacy and, more generally, conditions under which the central bank can coordinate private agents on its desired outcome.

The following table sums up our main results.

\section{TABLE: PRICE DETERMINACY UNDER LIMITED ENFORCEMENT}

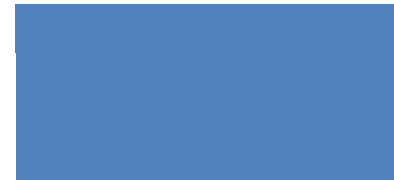

GENERAL

RESULTS

(for any policy)
The private sector expects a single policy
The private sector expects multiple policies

Price determinacy is never guaranteed (depends on the private sector beliefs)

Inflation remains always bounded

TAYLOR RULES
Unique equilibrium

$\&$

Price stability
Unique equilibrium \& price stability only if a sufficiently large share of private agents expect the Taylor rule

Limited enforcement: the central banker can only credibly commit to policies that are not « too harmful» ex post.

The Taylor rule: the nominal interest responds proportionally (and more than-one-for-one) to inflation changes

Our first key but intuitive result is that, when enforcement is limited, the equilibrium rate of inflation is bounded across all equilibria. Diverging inflation paths ultimately lead to unbounded losses that, if inflation is costly for the central banker, would push the central bank to deviate from his policy as the cost to deviate is bounded. This "off-equilibrium" incentive to deviate when inflation rates become too large arises even in the case where the central banker would not have the incentive to deviate from its first best outcome.

This simple result has three main implications in the context of monetary policy. First, it is necessary and sufficient to look for nominally-bounded equilibria to check determinacy. In the case of linear policies, this amounts to check Blanchard and Kahn (1980)'s conditions. Second, if enforcement is believed to be limited, there is no point trying to design rules aiming at ruling out unbounded nominal paths, as only bounded allocations matters for determinacy. Third, we show that, under limited enforcement, the Taylor principle -- the nominal interest rate has to respond by more than one-for-one to changes in inflation -- is both necessary and sufficient to ensure determinacy. 
But limited enforcement may also allow agents to anticipate other policies thus leading to alternative equilibria. In the end, the central bank may potentially fail to coordinate agents not on the outcome given a policy - as for determinacy - but simply on the policy. Using central banker's words, there is a risk of disanchoring: agents expecting other policies -- as potentially observed in survey expectations -- start having views on future outcomes inconsistent with the central bank's policy.

In this extended framework, we first show that there does not exist a policy that, whatever prior private agents' policy beliefs, would allow the central bank to solve the coordination failure and lead private agents' to change their beliefs accordingly. Prior policy beliefs determine the equilibrium that arises and the policymaker cannot always curb these policy beliefs to coordinate expectations on the desired policy.

Despite this negative result, we show that some rules may still have the power to curb some inconsistent policy beliefs. This happens under three conditions: i) private agents must hesitate only between policies that can be distinguished, ii) there is a sufficiently large number of agents expecting the central bank's desired policy and iii) the central bank's policy leads to sufficiently large long-term gains compared with the other policies expected by the private sector. Under these conditions, the central bank finds optimal to follow its intended rule, which ultimately leads all agents to update their policy beliefs. We provide examples of such recoordination of policy beliefs when prior beliefs are not too far from the intended rule in the context of the Taylor rule.

In the end, our paper suggests that standard determinacy problems are not as important as usually argued because limited enforcement reduces the set of equilibria. However, our results emphasize that coordinating private agents' beliefs on a particular policy is not always possible because agents' beliefs alter the central banker's incentives to follow through a given policy. We find situations in which there exists a threshold on policy beliefs below which the policymaker has no incentives to follow his desired policy: This echoes the regular emphasis put by central bankers on the risk of inflation disanchoring and on the monitoring of private agents' expectations as if they fear that nominal disanchoring were a non-linear mechanism alike a threshold switching.

\title{
De la Détermination des Prix et des Règles Monétaires lorsque 1'Engagement est Limité
}

\begin{abstract}
RÉSUMÉ
Cet article examine la capacité des règles de politique monétaire à coordonner les anticipations des agents privés lorsque la règle peut éventuellement être enfreinte. Nous montrons que la possibilité d'enfreindre la règle permet d'éviter les trajectoires divergentes d'inflation, de sorte que les variables nominales demeurent toujours bornées à l'équilibre. En particulier, cela rend le principe de Taylor nécessaire et suffisant pour la détermination des prix lorsque les agents s'attendent à une règle de Taylor. Toutefois, la possibilité d'enfreindre la règle peut aussi conduire les agents à anticiper rationnellement plusieurs politiques et nous montrons qu'en général il n'existe pas de règle politique capable de coordonner n'importe quelles croyances des agents privés sur celle-ci. Nous fournissons enfin des conditions suffisantes pour qu'une telle recoordination puisse avoir lieu.

Mots-clés : Règles Politiques, Détermination et Mise en Application Limitée

Les Documents de travail reflètent les idées personnelles de leurs auteurs et n'expriment pas nécessairement la position de la Banque de France. Ils sont disponibles sur publications.banque-france.fr
\end{abstract}




\section{Introduction}

Motivation Governments and central banks are more and more relying on rules to enhance the efficiency of their policies: ${ }^{1}$ Committing to a rule both allows to overcome potential time inconsistency problems and helps to coordinate private sector expectations on desired economic outcomes, by making policy decisions more transparent and more predictable.

The ability of rules to coordinate private sector expectations - known as the determinacy problem - has attracted a lot of attention in monetary economics since at least Sargent and Wallace (1975). The literature has proposed many policy rules, including sophisticated rules, supposed to ensure the existence of a unique equilibrium and hence price determinacy. ${ }^{2}$ In any of these proposals, determinacy is obtained by ensuring that the policy rule forces any expectations paths except one to violate at least one equilibrium condition deriving from the private sector's optimal reactions.

However, policymakers may sometimes prefer to breach rules - enforcement is unlikely to be unlimited- and, as noted by Cochrane (2011), it is unclear whether the policymaker is going to optimally stick to its policy rule along off-equilibrium paths ${ }^{3}$. And, so far, little attention had been paid on how this policy decision whether to optimally abandon a rule affects the set of equilibria and modifies the determinacy conditions. ${ }^{4}$

In this paper, we investigate the ability of policy rules to coordinate private agents when the incentives to follow through on rules are limited. We characterize the set of equilibria under limited enforcement and we provide conditions under which the expectation of a policy rule ensures price determinacy and, more generally, conditions under which the central bank can coordinate private agents on its desired outcome. In contrast with the previous literature, determinacy, if obtained, results from the central banker's optimal decision whether to stick to a policy rule and not from solving a set of equations resulting from the commitment to a

\footnotetext{
${ }^{1}$ In the case of monetary policy, see the Financial CHOICE Act of 2017 (H.R.10) TITLE X -Fed Oversight Reform and Modernization, that requires the FOMC to comply to a Taylor rule.

${ }^{2}$ See Leeper (1991); Taylor (1999); Clarida et al. (1999); Atkeson et al. (2010); Adao et al. (2011); Hall and Reis (2016); Christiano and Takahashi (2018) among many others.

${ }^{3}$ See Cochrane (2011) for how it applies to the different policy proposals as Adao et al. (2011) or Atkeson et al. (2010). Yet, Cochrane (2011) does not investigate the full implications of limited enforcement on the equilibrium set.

${ }^{4}$ Limited enforcement may also constrain the best outcome that policymakers can achieve and, so, the best rule that policymakers can follow. A recent contribution in the context of fiscal policy is Halac and Yared (2017) who analyze how limited enforcement constrains the best rule that policymakers can follow. In the context of monetary policy, the Ramsey outcome is usually found to be self-enforcing under plausible calibrations (see Loisel, 2008; Kurozumi, 2008, among others).
} 
given rule and the private sector's optimal decisions.

We find that limited enforcement makes standard determinacy problems less important because limited enforcement reduces the set of equilibria consistent with a given policy. In contrast, the more difficult problem is to coordinate private agents beliefs on a particular policy because agents' beliefs alter the central banker's incentives to follow through a given policy. Importantly, we find that these problems arise for any rules, including the ones that ensure determinacy under full commitment. We find situations in which there exists a threshold on policy beliefs below which the policymaker has no incentives to follow his desired policy: This echoes the regular emphasis put by central bankers on the risk of inflation disanchoring and on the monitoring of private agents' expectations as if they fear that nominal disanchoring were a non-linear mechanism alike a threshold switching. ${ }^{5}$

Setting To make our point, we consider the New Keynesian model with the simplest gametheoretic argument: we only require monetary policy to be subgame perfect (Section 2). In this simple setting, we characterize the set of equilibria when the private sector expects that the policymaker will follow a monetary policy rule. In each state of the world, the policymaker may default from sticking to the policy rule but at the cost of a potential harmful recoordination of private agents on a less socially desirable (self-enforcing) equilibrium. The cost of this recoordination then determines the central banker's incentives to stick to a policy and so, the credibility of the rule.

To obtain limited enforcement, we consider an equilibrium refinement where we require subgame perfect equilibria to be also robust to recoordination on the standard time-invariant discretionary equilibrium after a policy deviation. In the absence of such a refinement, the worst equilibrium leads to an unbounded loss which means that any policy is credible. ${ }^{6}$

We use this setting as this is the most simple one under which we can obtain our results. Our arguments can be extended to many extensions or alternatives to the standard newKeynesian model (heterogenous agents, limits to rational expectations, the inclusion of an explicit financial sector, alternative forms of price rigidities or even flexible price environment as in Section 5.4) or to any refinement of the game or the equilibrium definition that would lead to limited enforcement of policy rules.

\footnotetext{
${ }^{5}$ One of the arguments in favor of the Asset Purchase Programme by the Eurosystem was that it was supposed to "decisively underpin the firm anchoring of medium to long-term inflation expectations." (Draghi, 2015).

${ }^{6}$ We investigate the full credibility case in Appendix A. See also Section 2.3 for more elements to justify this equilibrium refinement.
} 
Limited credibility Our first key but intuitive result is that, when enforcement is limited, the equilibrium rate of inflation is bounded across all equilibria. Diverging inflation paths ultimately lead to unbounded losses that, if inflation is costly for the central banker, would push the central bank to deviate from his policy as the cost to deviate is bounded. This "offequilibrium" incentive to deviate when inflation rates become too large arises even in the case where the central banker would not have the incentive to deviate from its first best outcome.

This simple result has multiple important implications in the context of monetary policy. First, it is necessary and sufficient to look for (nominally-)bounded equilibria to check determinacy. In the case of linear policies, this amounts to check Blanchard and Kahn (1980)'s conditions. In this sense, limited enforcement decreases the size of the set of equilibria consistent with a given policy rule. Second, if enforcement is believed to be limited, there is no point trying to design rules aiming at ruling out unbounded nominal paths, as only bounded allocations matters for determinacy.

We then illustrate our findings using Taylor rules for which we show that, under limited enforcement, the Taylor principle - the nominal interest rate has to respond by more than one-for-one to changes in inflation - is both necessary and sufficient to ensure determinacy.

Coordinating policy beliefs If limited enforcement makes determinacy given a policy rule less of a problem, limited enforcement may also allow agents to anticipate other policies thus leading to alternative equilibria. In the end, the central bank may potentially fail to coordinate agents not on the outcome given a policy - as for determinacy - but simply on the policy. Using central banker's words, there is a risk of disanchoring: agents expecting other policies - as potentially observed in survey expectations - start having views on future outcomes inconsistent with the central bank's policy. ${ }^{7}$

In this extended framework, we first show that there does not exist a policy that, whatever prior private agents' policy beliefs, would allow the central bank to solve the coordination failure and lead private agents to change their beliefs accordingly. Prior policy beliefs determine the equilibrium that arises and the policymaker cannot always curb these policy beliefs to coordinate expectations on the desired policy.

Despite this negative result, we show that some rules may still have the power to curb some inconsistent policy beliefs. This happens under three conditions: i) private agents must hesitate only between policies that can be distinguished, ii) there is a sufficiently large number of agents expecting the central bank's desired policy and iii) the central bank's policy leads to sufficiently large long-term gains compared with the other policies expected by the private

\footnotetext{
${ }^{7}$ See, for instance, the discussion of US inflation expectations in the 70s by Leduc et al. (2007).
} 
sector. Under these conditions, the central bank finds optimal to follow its intended rule, which ultimately leads all agents to update their policy beliefs. We provide examples of such recoordination of policy beliefs when prior beliefs are not too far from the intended rule in the context of the Taylor rule.

Extensions We then extend our approach to account for the presence of a zero lower bound on nominal interest rates (Section 5.1). We show that the deflationary equilibrium resulting from this bound may still arise under limited enforcement, thus suggesting that hyperinflations are easier to fight than deflationary spirals.

We also extend our approach to account for the presence of shocks, both non-fundamental in the case where the Taylor principle fails (Section 5.2) and fundamental ones (Section 5.3). We show that non-fundamental fluctuations boundaries are connected to the degree of time-inconsistency in the central bank's preferences, thus bridging the identification of nonfundamental shocks in Clarida et al. (2000) with the standard view on inflation bias and time-consistency as in Barro and Gordon (1983).

Literature review Our paper is connected to several strands of the literature.

In many monetary models, multiple equilibria arise, including ones where inflation diverges, even when the central bank adopts an active policy - as the Taylor rule following the Taylor principle - as, for example, in Clarida et al. (1999); Woodford (2003) in the NewKeynesian model or in Sims (2013). Using New Keynesian words, interest-rate rules satisfying the Taylor principle prevents the economy from local indeterminacy, i.e. multiple bounded equilibria, but cannot guarantee global determinacy, i.e. alternative diverging equilibria. In response, the literature has suggested different complements or alternatives to monetary policy that may restore nominal anchoring. Active fiscal policy as in the fiscal theory of the price level (Leeper, 1991; Sims, 1994; Woodford, 1995), commitment to pegs to other currencies or commodities (Obstfeld and Rogoff, 1983) or simply rules that strongly respond to expectations (Loisel, 2009; Adao et al., 2011; Hall and Reis, 2016). In the case of Hall and Reis (2016), the response to expectations goes through conducting the interest payments on central bank's reserves. In contrast with this literature, we do not assume commitment. We show that, under limited enforcement, inflationary spirals are simply not equilibrium outcomes and there is no rule that can curb any policy beliefs and always force the coordination of private agents. Thus this means that these proposals of rules that prevent inflationary spirals under commitment are not necessarily relevant under limited enforcement.

In this line of papers, some papers have common features with our approach as Atkeson 
et al. (2010) who propose to switch from an interest-rate rule to money growth rule in the case of excessive inflation due to the interest-rate rule (see also the more recent proposal by Christiano and Takahashi, 2018). However, in our paper the exit of the normal-times rule results from sequential rationality and not from a commitment. This leads to very different results: first, the existence of a unique equilibrium with a given rule does not come from the violation of a feasibility condition off-equilibrium (in their case, a monetary rule associated with the equilibrium private sector's optimal decision ensures that diverging inflation cannot occur) but from the violation of the optimality condition of the central banker; second, as they assume commitment, there cannot be other equilibria with other policies in their approach, while we show that such uniqueness property cannot arise under limited enforcement, thus leading to new policy problems that cannot be apprehended under commitment.

Our paper is also connected to Campbell and Weber (2018) who argue that optimal monetary policy under discretion leads to a single equilibrium in the New Keynesian model. Yet, we show in Appendix A that the optimal discretionary policy is consistent with only one Markovian equilibrium but also with multiple non-Markovian hyperinflation equilibria.

The role of reputation for monetary policy was first introduced by Barro and Gordon (1983) to study the inflation bias stemming from the desire to maintain the unemployment rate below its natural rate. Other sources of time-inconsistency of monetary policy - that gives value to maintain the central bank's reputation - have been investigated as the stabilization bias. The role of reputation has been investigated by Chang (1998) and Ireland (1997) who study the sustainability of the Friedman rule in monetary models. ${ }^{8}$ Recent research has focused on the sustainability of the Ramsey allocation in the New-Keynesian model (see Kurozumi, 2008; Loisel, 2008; Sunakawa, 2015, among others) or Nakata (2018) and Barthélemy and Mengus (2018) in the presence of the zero lower bound. Their main result is that the Ramsey allocation is usually subgame perfect under plausible calibrations. Our main contribution with respect to this literature is that we focus on the ability of the central bank to coordinate private agents on a particular allocation using a policy, which requires to investigate the sustainability of the whole policy strategy and not only the sustainability of the desired allocation. Importantly, we show that limited credibility has an impact on the implementation of monetary policy, even when limited credibility does not constrain the optimal allocation.

\footnotetext{
${ }^{8}$ See also Abreu (1988) or Abreu et al. (1990) on repeated games and Phelan and Stacchetti (2001) for the application to the Ramsey tax model. In our context, we are able to determine the worst subgame perfect equilibrium without investigating the full set of equilibria as in Abreu et al. (1990).
} 


\section{Environment}

In this section, we lay out the model and define the equilibrium concept.

\section{$2.1 \quad$ Model}

Time is discrete and takes value in $t \in\{0, \ldots, \infty\}$. The private sector behavior is captured by two equations:

$$
\begin{aligned}
& \pi_{t}=\beta \pi_{t+1}^{e}+\kappa y_{t}, \\
& y_{t}=y_{t+1}^{e}-\frac{1}{\alpha}\left(i_{t}-\pi_{t+1}^{e}\right),
\end{aligned}
$$

where $\pi_{t}$ denotes inflation, $y_{t}$ the output gap and $i_{t}$ the nominal interest rate at date $t$. Parameters $\alpha, \beta$ and $\kappa$ are positive constants. The variables $\pi_{t+1}^{e}$ and $y_{t+1}^{e}$ denote the date-t private sector expectations of inflation and output gap at date $t+1$.

These two equations can be viewed as linearized first-order conditions of private agents in a sticky price environment. The new-Keynesian Phillips curve (NKPC) describes the dynamics of prices. $^{9}$ The Euler equation (EE) sums up the consumer's inter temporal consumption choice. We introduce shocks in Section 5.3.

Definition 1. We say that the pair $\left\{\pi_{t}, y_{t}\right\}$ is a date-t competitive equilibrium given policy decision $i_{t}$ and expectations $\left\{\pi_{t+1}^{e}, y_{t+1}^{e}\right\}$ when $\left\{\pi_{t}, y_{t}\right\}$ solves (NKPC) and (EE), given $\left\{i_{t}, \pi_{t+1}^{e}, y_{t+1}^{e}\right\}$.

Welfare We assume that date-t social welfare, $W_{t}$, is the expected discounted sum of instantaneous welfare functions $U_{s}$ for $s \in\{t, \ldots, \infty\}$ :

$$
W_{t}=E_{t} \sum_{s=t}^{\infty} \beta^{s-t} U_{s}, \text { with } U_{s}=-\left(\pi_{s}^{2}+\lambda\left(y_{s}-y^{*}\right)^{2}\right),
$$

where the scalar $y^{*} \geq 0$ is the desired level of the output gap -at the root of the so-called inflation bias under discretion- and the scalar $\lambda$ measures the weight of output gap fluctuations in the loss function. The operator $E_{t}$ denotes the expectations operator given date-t central bank information.

Let us shortly comment about this welfare function. First, and more importantly, while this objective function looks familiar in the New-Keynesian literature, it is beyond the scope of

\footnotetext{
${ }^{9}$ Throughout the paper, we assume that this equation is invariant to trend inflation to keep tractability. We refer the interested reader to Ascari and Sbordone (2014) for more details about the validity of this equation outside the 0-inflation steady state.
} 
the paper to derive such a welfare function as an approximation of the utility of private agents in our context as this is done by Woodford (2003) near the 0-inflation steady-state. As this will become clearer, the only important assumption is that inflation enters the policymaker's preferences. ${ }^{10}$

Second, the source of an inflation bias $\left(y^{*} \geq 0\right)$ is going to be a useful parameter to manipulate the incentives to deviate of the central banker. ${ }^{11}$ But, importantly, all our results that are robust to considering $y^{*}=0: y^{*}>0$ leads to the time-inconsistency of the 0 -inflation allocation but we are more interested in the time consistency of out-of-equilibrium outcomes, which may happen also when $y^{*}=0$.

\subsection{Subgame perfect equilibrium}

Let us now introduce the game-theoretic structure and the definition of a subgame perfect equilibrium in our setting.

The actions and the timing of the game are as follows: first, private agents form their expectations for all future periods rationally, then, the central bank optimally sets the nominal interest rate, finally, private agents choose the current level of consumption and inflation competitively, which results into equations (NKPC) and (EE) ${ }^{12}$

More precisely, we denote by the sequence $h_{t-1}=\left\{\pi_{\tau}, y_{\tau}, i_{\tau}, \tau<t\right\}$ the history prior to period $t$. For any expectations rule $f=\left(f_{0}, f_{1} \ldots\right)$, we denote by $f^{t}=\left(f_{t}, f_{t+1} \ldots\right)$ the continuation of the expectations rule at time $t$, where $f_{t}\left(h_{t-1}\right)$ denotes private agents expectations $\left\{\pi_{t+1}^{e}, y_{t+1}^{e}\right\}$. Expectations at time $t$ only depend on variables at time $t-1$ because of the timing of the game and the absence of shocks - in Section 5.3, these expectations also include current shock.

Similarly, we denote by $\sigma$ the policy strategy of the central bank and by $\sigma^{t}$ its continuation. The policy strategy $\sigma_{t}$ depends on the history $h_{t-1}$ but also on private agents expectations, $\left\{\pi_{t+1}^{e}, y_{t+1}^{e}\right\}$ that are supposed observable at the time of the decision. Thus, $i_{t}=\sigma_{t}\left(h_{t-1}, \pi_{t+1}^{e}, y_{t+1}^{e}\right)$. Finally, private agents choose the level of the output gap and inflation at date $t$ as a function of their expectations $\left\{\pi_{t+1}^{e}, y_{t+1}^{e}\right\}$ and the current interest rate $i_{t}$. Note that, since the first order conditions of private agents are forward-looking, in equi-

\footnotetext{
${ }^{10}$ See Debortoli et al. (forthcoming) for a recent analysis of central bankers' objective functions.

${ }^{11}$ We consider this source of time-inconsistency mostly for tractability reasons, but we do not see why our results would not naturally extend to other sources of time-inconsistencies such as the stabilization bias. Yet, to determine the exact source of time-inconsistency is beyond the scope of this paper. See also Nuno and Thomas (2017) or Challe (2017) for microfoundations of the inflation bias in a heterogenous agent setting.

${ }^{12}$ An underlying assumption is that private agents are all identical, anonymous, choose symmetric strategies and decide both prices -as shareholders of firms- and quantities -as households.
} 
librium, inflation and the output gap will only depend on $h_{t-1}$ through expectations and the policy strategy.

We can now describe how each decision is determined, before presenting a formal definition of a subgame perfect equilibrium. We present these actions by starting from the end of the period $t$.

The history induced by the continuation of the policy plan $\sigma^{t}$ and the continuation of the expectations rule $f^{t}$, after an history $h_{t-1}$, follows:

$$
\begin{aligned}
& h_{t}=\left\{h_{t-1}, \ldots\right. \\
& \ldots \pi\left(f_{t}\left(h_{t-1}\right), \sigma_{t}\left(h_{t-1}, f_{t}\left(h_{t-1}\right)\right), y\left(f_{t}\left(h_{t-1}\right), \sigma_{t}\left(h_{t-1}, f_{t}\left(h_{t-1}\right)\right)\right), \sigma_{t}\left(h_{t-1}, f_{t}\left(h_{t-1}\right)\right)\right\},
\end{aligned}
$$

where the functions $\pi($.$) and y($.$) are the unique mappings from the triplet \left(\pi_{t+1}^{e}, y_{t+1}^{e}, i_{t}\right)$ to $\pi_{t}$ and $y_{t}$ defined by equations (NKPC) and (EE). Notice that because the model is stationary, these mappings are time-invariant.

We focus on rational expectations in a deterministic setting and therefore expectations of agents are always correct in equilibrium. Given an history $h_{t-1}$ and a policy strategy $\sigma$, the continuation of the expectations rule satisfy rational expectations:

$$
f_{t}\left(h_{t-1}\right)=\left[\pi \left(f_{t+1}\left(h_{t}\right), \sigma_{t+1}\left(h_{t}, f_{t+1}\left(h_{t}\right)\right), y\left(f_{t+1}\left(h_{t}\right), \sigma_{t+1}\left(h_{t}, f_{t+1}\left(h_{t}\right)\right)\right],\right.\right.
$$

where $h_{t}$ is induced by $h_{t-1}$ following equation (2).

Finally, the policymaker chooses the continuation of the policy strategy $\sigma^{t}$ given an history $h_{t-1}$ and the continuation of expectations $f^{t}$ to maximize social welfare:

$$
\begin{array}{r}
\max _{\sigma_{\tau}, \tau \geq t}-\sum_{\tau=t}^{\infty} \beta^{\tau-t}\left[\pi\left(f_{\tau}\left(h_{\tau-1}\right), \sigma_{\tau}\left(h_{\tau-1}, f_{\tau}\left(h_{\tau-1}\right)\right)\right)^{2}+\ldots\right. \\
\left.\ldots \lambda\left(y\left(f_{\tau}\left(h_{\tau-1}\right), \sigma_{\tau}\left(h_{\tau-1}, f_{\tau}\left(h_{\tau-1}\right)\right)\right)-y^{*}\right)^{2}\right]
\end{array}
$$

where, for any $\tau \geq t$, the history $h_{\tau}$ is induced by the history $h_{\tau-1}$ according to equation (2).

This allows us to define a subgame perfect equilibrium as follows:

Definition 2 (Subgame Perfect Equilibrium). An equilibrium is a policy strategy $\sigma$ and an expectations rule $f$ such that, for every date $t$ and for every history $h_{t-1}$ :

(i) [Optimal policy] Given the expectations rule $f$, the continuation of the policy strategy $\sigma^{t}$ solves the central bank problem (4);

(ii) [Competitive equilibrium] Given the policy strategy $\sigma$ and the expectations rule $f$, the pair $\left\{\pi_{t}, y_{t}\right\}$ is a date-t competitive equilibrium. 
(iii) [Rational expectations] Given the policy strategy $\sigma$, the continuation of the expectations rule $f^{t}$ satisfies equation (3).

We define an allocation as a sequence compatible with the private sector optimal decisions and rational expectations and we are interested in the allocations that are the outcome of a subgame perfect equilibrium as defined above.

Definition 3. An allocation is a sequence $\left\{\pi_{t}, y_{t}, i_{t}\right\}_{t \geq 0}$ solving (NKPC) and (EE) where, for all $t \geq 0, \pi_{t+1}^{e}=\pi_{t+1}$ and $y_{t+1}^{e}=y_{t+1}$.

We say that an allocation is the outcome of a subgame perfect equilibrium $(\sigma, f)$ if, at each date $t$ and for the history $h_{t-1}=\left\{\pi_{\tau}, y_{\tau}, i_{\tau}\right\}_{\tau \in\{0, \ldots, t-1\}}$ :

(i) The policy strategy satisfies $\sigma_{t}\left(h_{t-1}, \pi_{t+1}, y_{t+1}\right)=i_{t}$,

(ii) The expectations rule satisfies $f_{t}\left(h_{t-1}\right)=\left\{\pi_{t+1}, y_{t+1}\right\}$,

\subsection{Limited credibility equilibria}

We are primarily interested in situations where the credibility of the central banker is limited, that is when the central banker may be sometimes better off deviating and then punished by the private sector. Yet, to analyse such situations, the set of subgame perfect equilibria is too large: we show in the appendix that the worst equilibrium leads to an infinite loss and so any feasible outcomes may be equilibrium, even where deviations may lead to infinite gains from deviating - in short, credibility is unlimited in the whole set of SPEs.

Thus, to think about limited credibility, we refine the equilibrium definition by requiring that the equilibrium is robust to considering recoordination on the time-invariant discretionary equilibrium after a policy deviation. More formally:

Definition 4. A Limited Credibility equilibrium or LC-equilibrium is a subgame perfect equilibrium $(\sigma, f)$ such that the resulting allocation $\left\{\pi_{s}, y_{s}, i_{s}\right\}_{t \geq 0}$ satisfies, at each date-t and after any history $h_{t-1}$, the following condition:

$$
W_{t}\left(\left\{\pi_{s}, y_{s}, i_{s}\right\}_{s \geq t}\right) \geq \max _{i}\left[U_{t}\left(\pi\left(\pi_{t+1}, y_{t+1}, i\right), y\left(\pi_{t+1}, y_{t+1}, i\right)\right)\right]+\beta W^{D},
$$

where $W^{D}$ is the discounted loss associated with the time-invariant discretionary equilibrium.

To clarify, the left-hand-side infinite sum of (SUST) corresponds to the date-t welfare evaluated along the allocation. The first right-hand-side member corresponds to the best instantaneous welfare given expectations consistent with the date- $t+1$ allocation and the second member corresponds to the welfare in the time-invariant discretionary equilibrium. 
Why considering this specific refinement? In principle, any refinement where the recoordination after a deviation leads to a bounded loss for the central banker produces limited credibility: then if the gains from deviating become sufficiently large, the central banker can be better off defaulting and, thus, he is not credible to follow through on anything. The time-invariant discretionary equilibrium implies a bounded loss ( $W^{D}$ is bounded ) and we do not see any loss of generality to consider this specific equilibrium to introduce such a bounded loss. This assumption about the equilibrium after a policy deviation is widespread in the literature: see Kurozumi (2008), Loisel (2008), Nakata (2018) or Barthélemy and Mengus (2018) among others.

But there is also another reason why we consider this refinement. To be consistent with the idea of subgame perfection, we want to have a refinement where agents recoordinate after a deviation on something that is also an equilibrium, not only following the definition of the subgame perfect equilibrium, but according to the refined definition of an equilibrium. Said differently, we want that agents recoordinate on an equilibrium which implies a bounded loss for the central banker but which is also self-enforcing. The time-invariant discretionary equilibrium naturally satisfies this second requirement: it is indeed self-enforcing so that the time-invariant discretionary equilibrium is also a LC-equilibrium.

Finally, note that this focus on the time-invariant discretionary equilibrium can also be justified as being consistent with the standard renegotiation-proofness approach in repeated games. This equilibrium is indeed the best Markovian equilibrium from private agents' point of view and it is thus as if we allow a subset of players (all the private agents with the exception of the central banker) to renegotiate, but excluding the central banker who is forced to play under discretion. ${ }^{13}$ This refinement then parallels the literature on sovereign debt that has analyzed the sustainability of sovereign debt depending on punishment schemes (see Eaton and Gersovitz, 1981; Bulow and Rogoff, 1989; Kletzer and Wright, 2000).

Remark. In the case of a conservative central banker $(\lambda=0)$, the set of subgame perfect equilibria as previously defined and the set of LC-equilibria coincide and boil down to a unique allocation $\left(\pi_{t}=0\right.$, for all period $\left.\mathrm{t}\right)$. Similarly, in the absence of a source of timeinconsistency $\left(y^{*}=0\right)$, the time-invariant discretionary equilibrium is defined by $\pi_{t}=0$ for any $t \geq 0$. Therefore, the set of LC-equilibria also boils down to the 0-inflation equilibrium.

\footnotetext{
${ }^{13}$ This differs from the standard approach of renegotiation-proofness where all agents are able to renegotiatiate. The exact foundation of such a form of renegotiation-proofness is, however, beyond the scope of the paper as we are only interested in the resulting outcome, which is limited credibility.
} 


\section{$3 \quad$ Limited credibility equilibria}

In this section, we first show how limited credibility affects the whole set of equilibria: in any equilibrium inflation remains bounded. We then explore the implications for determinacy. We finally provide an application for Taylor rules.

\subsection{Inflation in limited credibility equilibria}

Let us investigate how the constraint (SUST) restricts the set of equilibrium allocations and how it affects inflation. Unbounded inflation leads to very low and unbounded levels of welfare, which ultimately fall well below the bounded level of welfare obtained by deviating and recoordinating on the time-invariant discretionary equilibrium. As a result, when inflation is diverging, there is always a date at which the central bank optimally deviates from its policy. We show that this implies that inflation should remain bounded in any LC-equilibrium.

Proposition 1. There exists $0 \leq M<\infty$ such that any allocation resulting from a $L C$ equilibrium features bounded inflation, that is for all $t \geq 0, \quad\left|\pi_{t}\right|<M$.

Proof. See Appendix F.1.

To obtain this result, we need two important ingredients. The first one is that diverging inflation leads to unbounded welfare loss as this happens with our specification of the welfare function. More generally, a necessary condition is that the central bank's objective function includes inflation. The second ingredient is limited credibility that bounds the level of welfare loss that the central bank may tolerate. However, this result does not depend on the exact value of this bound and hence does not rely on the equilibrium refinement that we have introduced.

Let us also mention what is not important to obtain that result. This result does not depend on how much the central bank weights future outcomes (the discount factor $\beta$ ). The result even holds true when the central bank is myopic $(\beta=0)$. This has a very simple explanation: what rules out diverging inflation is not a policy decision taken at date-0 by a forward looking authority (as in Atkeson et al. (2010) for example) but the expectation by the private sector of a future optimal policy decision. This result does not depend on the weight on the output gap $(\lambda)$, the size of the source of inflation bias $\left(y^{*}\right)$ or any other parameters: to rule out diverging inflation paths, it is not so important to know when the central banker will deviate - which would depend on all these parameters - but simply that it will deviate at some point. 
In the end, Proposition 1 introduces a kind of transversality condition for nominal variables. In contrast with transversality conditions for real variables that usually appear from optimal private choices, this condition appears from time-consistent optimal public choices.

\subsection{Determinacy with limited credibility equilibria}

A standard question in macroeconomics is whether a policy is consistent with a single equilibrium or whether multiple equilibria are possible. When the policy accepts a unique equilibrium, the policy is said to ensure determinacy or formally:

Definition 5 (Determinacy). A policy $\sigma$ ensures determinacy when there exists a unique expectations rule $f$ so that $(\sigma, f)$ is a $L C$-equilibrium.

The consequence of Proposition 1 is that the set of possible equilibria consistent with a given policy $\sigma$ has also to feature bounded inflation. Thus, by solving for the allocations compatible with the policy and where inflation remains bounded is sufficient to find the only equilibrium allocation. The following proposition formally states this consequence:

Proposition 2. A policy $\sigma$ ensures determinacy if and only if there exists a single bounded allocation compatible with the policy $\sigma$.

This proposition is a direct implication of Proposition 1 for policy strategies. If a policy $\sigma$ ensures determinacy, then there exists in equilibrium a unique allocation compatible with the policy $\sigma$. This allocation is bounded because of Proposition 1. Conversely, if there exists a unique bounded allocation compatible with the policy $\sigma$ then the policy ensures determinacy because any equilibrium outcome should be bounded.

A consequence of Proposition 2 is that, to check whether a policy leads to determinacy, it is sufficient to determine the set of bounded allocations compatible with the policy. When the policy strategy $\sigma$ is linear, this amounts to follow the standard procedure in linear rational expectations models as initiated by Blanchard and Kahn (1980).

This proposition also shows that, when credibility is limited, it is useless to look for policies that rules out diverging paths (as in Loisel, 2009; Hall and Reis, 2016; Atkeson et al., 2010), as these paths are simply not equilibrium outcomes.

\subsection{Application to Taylor rules}

In this subsection, we investigate how Propositions 1 and 2 can be applied to the context of Taylor rules. We first specify the rule in terms of a policy strategy and we then characterize the set of equilibrium compatible with this policy. 
Taylor rule strategies To make things simple, we consider a simplified version of the Taylor rule (Taylor, 1993):

$$
i_{t}=\phi \pi_{t}
$$

where the positive scalar $\phi$ measures the reactiveness of the nominal interest rate to inflation. To make the Taylor rule consistent with the timing of the game, we rewrite it as a function of private agents' expectations using the equations (NKPC) and (EE):

$$
i_{t}=\sigma_{t}^{T R}\left(h_{t}, y_{t+1}^{e}, \pi_{t+1}^{e}\right)=\phi \frac{\kappa y_{t+1}^{e}+(\beta+\kappa / \sigma) \pi_{t+1}^{e}}{1+\phi \kappa / \sigma} .
$$

This latest equation defines a policy strategy $\sigma_{t}^{T R}$ that consists of adhering to the Taylor rule.

Taylor rule allocations We say that an allocation $\left\{\pi_{t}, y_{t}, i_{t}\right\}_{t}$ is implemented by the Taylor rule when this allocation satisfies (NKPC), (EE) and (TR) for any $t$.

When the policy parameter $\phi$ is greater than 1 - this condition is known as the Taylor principle Woodford (2003)- multiple allocations satisfy these conditions: the 0-inflation allocation $\left(\pi_{t}=0\right.$ for any $\left.t \geq 0\right)$, but also allocations where inflation is diverging. All the allocations except the 0-inflation allocation are exploding because the Taylor principle ensures that all the eigenvalues of the dynamic system are above one. More formally, any allocations satisfying the Taylor rule feature:

- Either for all $t \geq 0, \pi_{t}=y_{t}=0$;

- Or for any $M>0$, there exists $t>0$ such that $\left|\pi_{t}\right|>M$.

In the following, we make the following assumption;

Assumption 1. The 0-inflation allocation is sustained by a LC-equilibrium.

We clarify in Appendix $\mathrm{C}$ the conditions under which the assumption is satisfied.

Determinacy We now prove that the Taylor principle ensures the uniqueness of LC-equilibria where the policy instrument $i_{t}$ is set following a Taylor rule strategy.

Proposition 3. $\sigma^{T R}$ ensures determinacy, that is there exists a unique LC-equilibrium where the Taylor rule strategy is followed, if and only if the Taylor principle $(\phi>1)$ is satisfied.

Proof. See Appendix F.2. 
Proposition 3 directly results from Proposition 1. Any allocation consistent with the Taylor rule that does not coincide with the 0-inflation allocation features diverging inflation if and only if the response to inflation is greater than one-for one $(\phi>1)$. Yet, as noted by Proposition 1, along such diverging paths, the central banker is better off deviating from the Taylor rule at some finite date in the future. Thus such an allocation cannot be the outcome of a LC-equilibrium.

In contrast, under full credibility (Appendix A), there is no such incentives to deviate thus giving rise to multiple equilibria consistent with Taylor rules, including many where inflation is diverging. This also stands in sharp contrast with the situation where the Taylor principle is not satisfied (Section 5.2), in which case multiple LC-equilibria are consistent with the Taylor rule.

Finally, in Appendix B, we extend Proposition 3 by showing that there does not exist LC-equilibria where the policy strategy consists in following the Taylor rule in the short run and then abandoning it to switch to the discretionary policy: if the private sector expects the central banker not to follow the Taylor rule in the long run, the central banker has no incentive to follow the Taylor rule in the short run.

\section{The role of policy beliefs}

In the previous section we provide conditions under which a policy strategy leads to determinacy. These conditions are obtained assuming that private agents expect the considered policy strategy. But what happens if private agents expect something else? Is there any policy that, when implemented, ensures that private agents do expect it? To answer these questions, we extend in this section our equilibrium concept to introduce private sector's beliefs about the policy.

Our first finding is that there does not exist a policy which allows the policymaker to force the equilibrium outcome: there always exist policy beliefs leading to an equilibrium outcome where the policymaker does not play his desired policy. We then show that the policymaker may however opt to follow through his desired rule when policy beliefs only slightly depart from the desired rule. We finally apply these results to Taylor rules.

\subsection{Limited credibility equilibrium with policy beliefs}

We introduce dispersed policy beliefs by assuming that the private sector is composed of a continuum of mass one individuals who have potentially dispersed beliefs about future 
policies. At the outset of date 0 , each individual $i \in(0,1)$ has subjective prior beliefs denoted by $P_{-1}^{i}(\sigma)$ that the policy implemented by the central bank is $\sigma \in \Sigma$, where $\Sigma$ denotes the set of policy strategy profiles. Then private agents observe other beliefs and can revise their beliefs. We denote by $P_{t}^{i}\left(\sigma, h_{t-1}\right)$ the date-t policy beliefs of agent $i$ that implemented policy is $\sigma$ after an history $h_{t-1} \cdot{ }^{14}$ The belief profile is $\left\{P^{i}\right\}_{i \in(0,1)} \equiv\left\{\left\{P_{\tau}^{i}\right\}_{\tau \geq 0}\right\}_{i \in(0,1)}$.

Based on their date-t policy beliefs, any agent $i$ forms rational expectations about date- $t+1$ inflation and output gap:

$$
\begin{aligned}
f_{t}^{i}\left(h_{t-1}\right)= & {\left[\sum_{\sigma \in \Sigma} P_{t}^{i}\left(\sigma, h_{t-1}\right) \pi\left(f_{t+1}^{i}\left(h_{t}\right), \sigma_{t+1}\left(h_{t}, f_{t+1}^{i}\left(h_{t}\right)\right)\right),\right.} \\
& \left.\sum_{\sigma \in \Sigma} P_{t}^{i}\left(\sigma, h_{t-1}\right) y\left(f_{t+1}^{i}\left(h_{t}\right), \sigma_{t+1}\left(h_{t}, f_{t+1}^{i}\left(h_{t}\right)\right)\right)\right],
\end{aligned}
$$

where the history $h_{t}$ is the history induced by $h_{t-1}$, the policy strategy $\sigma_{t}$, and the expectations rule $f_{t}^{i}$ as in equation (2). Notice that date-t history $h_{t}$ depends on the policy strategy $\sigma$ and thus changes from one term of the summation to another term.

This allows us to define an equilibrium in this more general setting.

Definition 6. Given prior beliefs $\left\{P_{-1}^{i}\right\}$, a perfect Bayesian equilibrium is a belief profile $\left\{P^{i}\right\}_{i \in(0,1)}$, expectation rules $\left\{f^{i}\right\}_{i \in(0,1)}$ and a policy strategy $\sigma$ such that, at each date-t and after any history $h_{t-1}$ :

(i) [Optimal policy] Given expectations rules $\left\{f^{i}\right\}_{i \in(0,1)}$, the continuation of the policy plan $\sigma^{t}$ solves central bank's problem (4);

(ii) [Competitive equilibrium] Given the policy plan $\sigma$ and expectations rules $\left\{f^{i}\right\}_{i \in(0,1)}$, the couple $\left\{\pi_{t}, y_{t}\right\}$ is a date-t competitive equilibrium.

(iii) [Rational expectations] Given the set of beliefs $\left\{P_{t}^{i}\left(., h_{t-1}\right)\right\}$, the expectations rule $f^{i}$ satisfy (6).

(iv) [Beliefs updating] Given the set of beliefs $\left\{P_{t}^{i}\left(., h_{t-1}\right)\right\}$, the beliefs $\left\{P_{t+1}^{i}\left(., h_{t}\right)\right\}$ satisfy the Bayes' law whenever possible.

As in the previous section, we limit the possible set of equilibria on which private agents can recoordinate to limit the credibility of the central bank. The equilibrium should be also sustainable if private agents recoordinate on the time-invariant discretionary equilibrium after a policy deviation, i.e. if the policymaker sets a policy that does not belong to the support of policy beliefs.

\footnotetext{
${ }^{14}$ To avoid cumbersome notations, we omit the potential dependence of date-t beliefs on past beliefs.
} 
Definition 7. For $\left\{P_{-1}^{i}\right\}$ on a common countable support $S(\Sigma)$, a Limited Credibility perfect Bayesian equilibrium or LCB-equilibrium is a perfect Bayesian equilibrium $(\sigma, f, P)$ such that the resulting allocation satisfies inequality (SUST) at each date $t$ and after any history $h_{t-1}$.

Notice that our definition of LCB-equilibria is consistent with our previous definition of LC-equilibrium as any LC-equilibrium defined in Section 3 is also a LCB-equilibrium for which the prior beliefs $\left\{P_{-1}^{i}\right\}$ is a collection of dirac functions that all peaks at the policy $\sigma$.

To start with, let us make sure that our result on inflation boundedness for SPE is robust to considering policy beliefs. The following proposition establishes such a results when agents hesitate between an infinite but countable number of policies:

Proposition 4. Any LCB-equilibrium with prior beliefs $\left\{P_{-1}^{i}\right\}$ on a common countable support $S(\Sigma)$ leads to an allocation in which inflation is bounded.

Proof. See Appendix F.3

Uncertainty about future policies cannot be the source of unbounded inflation paths. When inflation diverges along an allocation, the central banker has an incentive to deviate at some point from the policy leading to this diverging path to force the recoordination on the time-invariant discretionary equilibrium. And, since we require that the support of prior beliefs is on a countable support, there always exists a policy action outside the support of policy beliefs that can be effectively interpreted by private agents as a deviation.

\subsection{Coordinating dispersed policy beliefs}

Let us investigate the set of equilibria when beliefs are dispersed. In particular, we are interested to know whether there exists a policy strategy that would be implemented whatever the initial prior beliefs of private agents.

Proposition 5. If $y^{*} \neq 0$ and $\lambda \neq 0$, then for any $\sigma$, there exists prior beliefs $\left\{P_{-1}^{i}\right\}$ such that none of the policy $\sigma_{t}$ is played in LCB-equilibrium.

Proof. See Appendix F.4

This Proposition is a straightforward result of the existence of multiple subgame perfect equilibria. As noted above each LC-equilibrium is also a LCB-equilibrium with specific prior policy beliefs. Besides, when $y^{*}>0$ and $\lambda>0$, we can identify at least two LC-equilibria with different policy strategies at any date: the discretionary policy and an arbitrary Taylor rule for instance. Therefore, there does not exist a policy strategy that is always played in equilibrium. 
If agents are unconvinced that the policymaker is going to adhere to a given policy, there is nothing that the policymaker can do to force them to believe about the intended policy. The underlying reason is that because the central banker's credibility is limited, beliefs inconsistent with a given policy may force the central banker to optimally implement another policy that he may want. This results is not peculiar to linear simple rules but means that we cannot expect policy rule to fundamentally solve equilibrium multiplicity if private agents do not believe in the policy rule intended to be followed through by the central bank.

Remark. The intra-period timing of the game is not essential for Proposition 5. Even if private agents form expectations after the central bank's action, the central banker can be forced to play a policy different from his desired one.

Weakly dispersed policy beliefs Let us now investigate what are the conditions under which a given policy desired by the central bank can be implemented in equilibrium.

Proposition 5 shows that there always exist policy beliefs such that a policy is not followed through in equilibrium. The key ingredient for obtaining this result is that policy beliefs give no weight to the considered policy. Thus a necessary condition for a policy to be implemented in equilibrium is that at least some agents initially expect it.

In the following proposition, we provide sufficient conditions under which the coordination may take place:

Proposition 6. For any (continuous) policy $\sigma \in \Sigma$ that ensures determinacy in the context of LC-equilibrium as in definition 5,

(i) If prior beliefs $\left\{P_{-1}^{i}\right\}$ feature a common finite support $S(\Sigma)$ (including $\sigma$ ),

(ii) If the unique LC-equilibrium compatible with $\sigma$ satisfies for any policy $\sigma^{\prime} \in S(\Sigma) \backslash\{\sigma\}$ :

$$
W_{0}\left(\left\{\pi_{t}, y_{t}, i_{t}\right\}_{t \geq 0}\right)>U_{0}\left(\pi\left(\pi_{1}, y_{1}, \sigma^{\prime}\left(\pi_{1}, y_{1}\right)\right), y\left(\pi_{1}, y_{1}, \sigma^{\prime}\left(\pi_{1}, y_{1}\right)\right)\right)+\beta W_{1}^{\prime},
$$

where $W_{1}^{\prime}$ is the highest welfare among the allocations resulting from a $L C$-equilibrium with policy $\sigma^{\prime}$.

then there exists $\bar{\gamma}<1$ such that if $\int_{0}^{1} P_{-1}^{i}(\sigma)>\bar{\gamma}$ there exists a unique LCB-equilibrium. The resulting equilibrium allocation coincides with the one resulting from the unique $L C$-equilibrium consistent with policy $\sigma$.

Proof. See Appendix F.5 
The first condition on beliefs ensures that by observing the policy actions the private agents can infer the policy. The second condition ensures that the long term gains to stick to the policy are sufficiently large so that the central banker does not prefer to switch to any other policy that can be expected by private agents.

More specifically, this latter condition states that, when private agents fully expect the policy $\sigma$, the central banker strictly prefers to adhere to policy $\sigma$ even if the policymaker could recoordinate future beliefs on any other policies included in the support of prior beliefs. Intuitively, this condition requires that the alternative policy is neither desirable in the short run -the incentive to deviate in the short run is low- nor desirable in the long run -the welfare of the considered equilibrium is higher than the one in potential LC equilibria with the other policy. If, for a given LC-equilibrium, the date-0 constraint (SUST) is slack, then the LC-equilibrium is robust to the discretionary policy.

Remark. Proposition 6 shows that when prior beliefs are sufficiently peaked on a policy ensuring determinacy, then beliefs immediately coordinate on the policy and the resulting equilibrium is unique and not altered by prior beliefs. Therefore, in equilibrium, we do not see the policymaker reacting to the out-of-equilibrium prior beliefs that another policy will be followed. To see how the policy should react "in equilibrium" to alternative beliefs, we need to relax some of our assumptions as, for example, the assumption of common knowledge. We provide some elements in this direction in the next subsection in the case of Taylor rules.

\subsection{Coordinating dispersed policy beliefs with a Taylor rule}

We now apply Proposition 6 to the Taylor rule strategy satisfying the Taylor principle $(\phi>1)$. To simplify the setting, we assume that private agents can only hesitate between the Taylor rule strategy $\sigma^{T R}$ and the discretionary policy $\sigma^{\text {disc }}$.

Proposition 7 provides some properties of the minimum weight put on the Taylor rule strategy needed to get the desired outcome, i.e., the 0-inflation allocation.

Proposition 7. Under Assumption 1, there exists a scalar $\bar{\gamma}<1$ such that for any prior beliefs verifying $\int_{0}^{1} P_{-1}^{i}\left(\sigma^{T R}\right) d i>\bar{\gamma}$ the unique equilibrium allocation is the 0-inflation allocation. The threshold $\bar{\gamma}$ does not depend on $y^{*}$. Otherwise, if $\int_{0}^{1} P_{-1}^{i}\left(\sigma^{T R}\right) d i<\bar{\gamma}$, the unique equilibrium outcome is the time-invariant discretionary allocation.

Proof. See Appendix F.6.

Proposition 7 is an application of Proposition 6 in the case of Taylor rules: Adhering to a Taylor rule satisfying the Taylor principle ensures determinacy not only when private agents 
expect it to be followed through (Proposition 3) but also when a sufficiently large share of agents believe that it will be the case, i.e., $\int_{0}^{1} P_{-1}^{i}\left(\sigma^{T R}\right) d i>\bar{\gamma}$. Proposition 6 applies here because we assume that the support of beliefs is finite, the Taylor rule satisfies the Taylor principle, and hence ensures determinacy when anticipated, and the welfare in the 0-inflation allocation is higher than the one with a discretionary policy.

However, as mentioned above, the uncertainty is off-equilibrium: once the agents observe the distribution of beliefs of other agents, they can immediately update their own beliefs. Naturally, one may wonder whether the central bank has still this ability to recoordinate expectations when agents cannot observe the distribution of beliefs but only some public signals as the policy decision - that is in a situation where there is no common knowledge between private agents. We extend these results to such an environment in Appendix E and we show that the central banker has still incentives to adhere to the Taylor rule even if private agents form beliefs that are not observable by others but only by the central banker. The key difference with proposition 7 is that the central bank reacts to expectations following the Taylor rule in equilibrium. Then, the Taylor rule is not only necessary as an out-ofequilibrium threat but also an in-equilibrium action useful to recoordinate private agents expectations through learning about other agents' beliefs.

\section{Extensions}

In this section, we investigate the consequences of limited credibility when enriching our environment. First, we include an effective lower bound on nominal interest rate. Second, we consider how limited credibility affects the multiplicity of equilibrium when the Taylor principle is not satisfied. Third, we extend our results to the presence of shocks. Fourth, we show that most of our findings are also valid in a flexible prices environment.

\subsection{Zero lower bound}

In this subsection, we extend our results to the presence of a lower bound on nominal interest rates. It is well known that the presence of such a bound leads to additional multiplicity of equilibria under commitment. The natural question is then whether limited enforcement, which rules out hyperinflations also rules out deflationary spirals. We investigate here whether the lower bound also lead the set of equilibria in our game to expand and, more precisely, we focus on the permanent liquidity trap as studied by Benhabib et al. (2001).

Proposition 8. The permanent liquidity trap equilibrium is an LC-equilibrium when $y^{*}$ is 
sufficiently large.

Proof. See Appendix F.7

The main step of the proof is to show that the loss in the permanent liquidity trap is bounded. When the cost of the discretionary equilibrium indexed by $y^{*}$ exceeds the cost of the permanent liquidity trap, it is sufficient to ensure that the permanent liquidity trap is a LC-equilibrium.

But Proposition 8 also means that, in contrast with hyperinflations, one cannot use asymptotic arguments anymore and whether the permanent liquidity trap is a LC-equilibrium is a quantitative question. Thus, being a LC-equilibrium highly depends on the refinement that we are using - this choice of refinement was mostly innocuous with hyperinflations. For example, one may use a refinement where the recoordination after a deviation is on the permanent liquidity trap, in which case the permanent liquidity trap itself would be always a LC-equilibrium.

Note also that, quantitatively, it is also unclear what is the most desirable: the permanent liquidity trap or the discretionary equilibrium.

In the end, all this discussion simply means that we cannot use limited enforcement arguments in a clear-cut way to rule out deflationary spirals as the permanent liquidity trap equilibrium.

Stability of the 0-inflation equilibrium The zero lower bound also modifies the ability of the Taylor principle to re-anchor expectations on the right policy through a learning process. As emphasized in the previous section, the learning process requires that desired policy leads to a single equilibrium. This is not the case anymore for the Taylor rule constrained by the ZLB, which produces multiple (LC-) equilibria.

In addition, there are another problem for which limited credibility cannot do anything for Taylor rules: these rules do not prevent inflation paths to diverge from regions close to 0-inflation to the permanent liquidity trap. This means that, if agents expect inflation to be a slightly different from zero, then the economy is going to converge to the permanent liquidity trap and the Taylor cannot prevent that divergence. As the permanent liquidity trap and the trajectory to this trap remain bounded, such divergence may still arise under limited credibility.

Arguably, this is not the case of several recent proposals for rules such the ones by Loisel (2009), Adao et al. (2011) or Hall and Reis (2016), that are, to some extent, able to prevent deflationary spirals that ultimately lead to the permanent liquidity trap, even under limited 
credibility. By requiring monetary policy to respond more to expectations, these rules guarantee that the economy do not diverge to the permanent liquidity trap, thus ensuring some local stability of the 0 -inflation equilibrium.

Under limited credibility and in the absence of a lower bound on nominal rates, Taylor rules are not inferior but equivalent to many proposed rules to ensure determinacy, as derived in the previous section. Yet, once introducing a lower bound on nominal rates, this equivalence breaks down and, even under limited credibility, some proposed rules that respond more to inflation expectations perform better than the Taylor rule. We thus suggest an alternative reading of the contribution of these alternative rules: they do not contribute to solving the price-level determinacy problem but help to avoid self-fulfilling liquidity trap expectations.

\subsection{Limited credibility outside the Taylor principle}

In this subsection, we further investigate how limited credibility modifies the equilibrium outcome when the central bank is expected to follow a Taylor rule that does not satisfy the Taylor principle. As already mentioned, such a policy leads to multiple equilibria. We show in this subsection that limited credibility limits non-fundamental fluctuations.

Proposition 9. When the Taylor principle is not satisfied $(\phi<1)$, there exist many $L C$ equilibria consistent with a Taylor rule strategy:

(ii) the 0-inflation allocation,

(iii) self-fulfilling prophecies equilibrium described as follows:

$$
\pi_{t}=\lambda_{1}^{t} \pi_{0}, \quad \text { and } \quad y_{t}=\lambda_{1}^{t} \omega \pi_{0},
$$

where the initial level of inflation $\pi_{0}$ is any scalar in $[\underline{\pi}, \bar{\pi}]$, the scalar $\lambda_{1}$ is the stable eigenvalue of the three-equation system and the scalar $\omega$ denotes the relative weight of the associated eigenvector to the output gap (see Appendix F.8 for formal definitions).

Furthermore, the upper (lower) bound for inflation $\bar{\pi}(\underline{\pi})$ increases (resp. decreases) with the inflation bias $y^{*}$.

Proof. See Appendix F.8.

Limited credibility rules out two types of inflation paths, those that are diverging -in which inflation and the output gap belong to the unstable eigenvector- and those with a too high inflation initial level -with a too large initial inflation level $\pi_{0}$. 
Limited credibility also restricts the range of fluctuations of inflation. In our setting, this range depends on the inflation bias. Indeed, the social welfare in the worst equilibrium increases with this bias. So, the higher the bias, the more costly the abandon of the Taylor rule is, making higher expectations subgame perfect. As far as we know, this is the first time such a connection is established. This result suggests that adhering to the Taylor principle is more crucial when the policymaker suffers from a high level of time-inconsistency, but is less crucial when the policymaker is more conservative.

This latter result connects the two approaches of high and volatile inflation periods such as the 70s: the presence of non-fundamental shocks as in Clarida et al. (2000) and Lubik and Schorfheide (2004) and the presence of an inflation bias in the central bank's preferences as in Barro and Gordon (1983): non-fundamental shocks resulting from the failure of the Taylor principle may arise only in the presence of such an inflation bias.

\subsection{Stochastic environment}

This section extends our results to a the presence of exogenous shocks. We show that the main condition for our results to go through is the way shocks also affects the discretionary equilibrium.

We incorporate shocks into the baseline model as follows:

$$
\begin{aligned}
\pi_{t} & =\beta E_{t} \pi_{t+1}+\kappa y_{t}+u_{t}, \\
y_{t} & =E_{t} y_{t+1}-\frac{1}{\sigma}\left(i_{t}-E_{t} \pi_{t+1}-r_{t}^{n}\right),
\end{aligned}
$$

where the random processes $u_{t}$ and $r_{t}^{n}$ denote cost-push shocks and natural interest rate shocks respectively. Besides, we assume that the central banker can arbitrary deviate from the Taylor rule as follows:

$$
i_{t}=\alpha \pi_{t}+\epsilon_{t}
$$

where $\epsilon_{t}$ is a monetary policy shock.

LC-equilibrium in a stochastic environment The timing is modified to take into account the stochastic property of the game. We now assume that the current shocks are known by private agents and by the central bank at each stage of the game. Thus expectations that they form as well as the policy plans implemented by the central bank are functions of these shocks. We also assume that private agents form expectations that are correct in average. More formally, we define a subgame perfect equilibrium in such an environment by including 
shocks in the state space, $h_{t-1}=\left\{\pi_{\tau}, y_{\tau}, i_{\tau}, u_{\tau}, r_{\tau}^{n}, \epsilon_{\tau}, \tau<t\right\}$ and assume that the right-handside member of equation (3) is replaced by an integral over all future shocks. We now define LC-equilibrium in such an environment.

The presence of shocks implies fluctuations in the time-invariant discretionary equilibrium. If shocks are bounded then the punishment equilibrium is bounded as well and so is any LCequilibrium, thus implying that all our previous results still hold. We extend this result to certain situations where shocks are unbounded:

Proposition 10. The distance between inflation in any $L C$-equilibrium and inflation in the time-invariant discretionary equilibrium remains bounded if:

(i) Shocks are bounded.

(ii) Shocks follow a first-order autoregressive process with second-order process innovation. ${ }^{15}$

Proof. See Appendix F.9.

In the following, we apply this result to validate the robustness of our benchmark results.

Taylor principle and the 'divine coincidence' If the natural interest rate shock, $r_{t}^{n}$, is the only shock affecting the economy and is incorporated in the Taylor rule (as suggested by Woodford, 2003; Gali, 2008) then propositions 3 is not modified. The Taylor principle guarantees the uniqueness of the equilibrium as long as private agents believe in the Taylor rule in the first place. Indeed, if the interest rate reacts by one-for-one to the natural interest rate shock, this latter shock disappears from the economy and no more affects inflation and the output gap. ${ }^{16}$

Suboptimal Taylor rules If the Taylor rule does not respond to the natural rate of interest $r_{t}^{n}$, if the economy is hit by a cost-push shock $u_{t}$ or if monetary policy deviates from the Taylor

\footnotetext{
${ }^{15}$ Formally, this embeds any autoregressive process such that: $x_{t}=\rho x_{t-1}+\nu_{t}$ with $\rho<1, E_{t} \nu_{t+1}=0$ and $E_{t}\left|\nu_{t+1}\right|^{2}<\infty$.

${ }^{16}$ If the Taylor principle is not satisfied, sunspot shocks can hit the economy:

$$
\left[\begin{array}{ll}
\pi_{t} & y_{t}
\end{array}\right]^{\prime}=V_{1} w_{1, t}, \text { where } w_{1, t+1}=\lambda_{1} w_{1, t}+\eta_{t+1}
$$

where $w_{1,0}$ corresponds to an (arbitrary) initial condition and the stochastic process $\eta_{t+1}$ is any bounded zero-mean process, sometimes referred to as sunspot shocks. In the existing literature, the variance and the support of this shock is unbounded. Limited credibility imposes the boundedness of sunspot shocks (as in Proposition 9).
} 
rule, then large shocks can generate an incentive for policy switching, the Taylor rule being suboptimal compared to the discretionary equilibrium (or the best deviation policy).

For simplicity, we suppose all shocks to be i.i.d. and zero-mean. We also assume that the variance of shocks is small compared to the inflation bias $y^{*}$. This latter assumption guarantees that the Taylor rule delivers a higher expected welfare relative to the one delivered by the time-invariant discretionary equilibrium. If this assumption is not verified, the Taylor rule will never be implemented in a LC-equilibrium.

Proposition 11. If shocks $\left(r^{n}, u, \epsilon\right)$ are not too large, the Taylor principle guarantees that there exists a unique LC-equilibrium implemented by the Taylor rule.

Proof. See Appendix F.10.

If shocks are not too large, central banker always prefers sticking to the Taylor rule and the Taylor rule implements a LC-equilibrium. Proposition 11 does not depend on the nature of shocks as the three kind of shocks we consider lead to some inefficiency of the Taylor rule.

On the contrary, when shocks are too large, then deviating from the Taylor rule policy triggers a short-term gain that dominates the long term gains of adhering to it and achieving the 0-inflation allocation (compared to the time-invariant discretionary allocation). The presence of large shocks may lead to allocations that are implemented by a Taylor rule in the short run but not in the long run. We now investigate the impact of such large shocks ex ante.

To simplify the exposition, we only assume large monetary policy shocks. Consider an economy in which monetary policy follows a Taylor rule (as long as it is optimal) that can be affected by a very large (positive or negative) monetary policy shock. The monetary policy shock is either 0 with probability $(1-p)$ or $\epsilon(-\epsilon)$ with probability $p / 2(p / 2$ resp.). We also assume that the size of the shock $\epsilon$ is so large that it always leads the central banker to switch to discretion.

Proposition 12. There exists a threshold $\bar{p}$, such that:

If $p<\bar{p}$, there exists a unique LC-equilibrium implemented by the Taylor rule (as long as the economy is not affected by the shock) if and only if the adjusted Taylor principle $\phi>1-p$ is verified. When the monetary policy shock is zero, inflation and the output gap increase with $p$ because of the anticipation of the inflation bias in the discretionary equilibrium.

If $p>\bar{p}$, the Taylor rule is never followed by the central banker.

Proof. See Appendix F.11. 
The higher the probability of a large shock, the lower the incentives the central banker has to stick to the Taylor rule. There exists a thresholds, $\bar{p}$, such that when the probability of large shocks is above the threshold $\bar{p}$, the central banker never follows the Taylor rule. Indeed, inflation and the output gap are closer and closer to the discretionary allocation when $p$ increases and the long-term gains of the Taylor rule decreases with $p$ (it is as if the discount factor of the central banker is lower).

\subsection{Flexible price environment}

In this subsection, we highlight how most of this paper's results can be still valid in the context of a flexible price model. The model features a Fisher equation linking private agents expectations and nominal interest rate and a central bank that targets zero inflation. The reader can find more details in Appendix D.

The environment The central bank is in charge of maintaining price stability. At date $t \geq 0$, the central bank seeks to maximize the objective function $W_{t}$ over the nominal interest rate $i_{t}$ :

$$
W_{t}=-\sum_{k \geq t} \beta^{k-t} E_{t}\left(\pi_{k}\right)^{2}
$$

where $\beta$ is the central banker's discount factor.

We assume that, in equilibrium, a Fisher equation holds for any $t \geq 0$ :

$$
i_{t}=E_{t} \pi_{t+1}+r
$$

where $E_{t} \pi_{t+1}$ the date-t expectations formed by private agents about future inflation and $r$ the risk-free real return. ${ }^{17}$ The private sector forms perfect foresight about future inflation rates, $E_{t} \pi_{t+1}=\pi_{t+1}$.

In the following, we consider a central bank adhering to a Taylor rule of the form:

$$
i_{t}=r+\phi \pi_{t}
$$

where the parameter $\phi$ is a positive scalar measuring the response of the nominal interest rate to inflation. In this subsection, we assume that the Taylor principle is satisfied, i.e. $\phi>1$.

Contrary to the rest of the paper's assumption, we suppose that the central bank sets its nominal interest rate based on the observed rate of inflation and the private sector sets its

\footnotetext{
${ }^{17}$ This equation can be micro-funded by a no-arbitrage condition when, at each date, risk-neutral households can choose to hold government bonds yielding a risk-free nominal return $i_{t}$ or real assets yielding a risk-free real return $r$. Without loss of generality, we assume that the return of the real asset is constant.
} 
expectation of future inflation rates so as to satisfy the Fisher equation. This different timing is necessary since in the flex-price model the current level of inflation does not appear in the first order conditions of the private sector. The precise timing is as follows:

(i) The private sector sets the inflation rate $\pi_{t}$,

(ii) The central bank sets the interest rate $i_{t}$, observing the current inflation rate,

(iii) The private sector observes the interest rate and forms expectation about the future inflation rate $E_{t} \pi_{t+1}$.

Equilibrium definition Let us now assume that the central bank does not have a commitment technology and that following a Taylor rule can only be the outcome of an equilibrium. In particular, let us define an equilibrium in this model as a sequence of current and expected inflation rates and nominal interest rates such that:

(i) At each date, given past histories and given private sector expectations, the central bank maximizes over its objective function.

(ii) Given past histories, private agents form rational expectations and equation (12) holds.

Characterizing of subgame perfect equilibria Let us first determine discretionary equilibria:

$$
\begin{aligned}
& \max _{\left\{i_{k}\right\}_{k \geq t}}-\sum_{k \geq t} \beta^{k-t}\left(\pi_{k}\right)^{2}, \\
& \text { s.t. } \forall k \geq t, \quad i_{k}=\pi_{k+1}+r
\end{aligned}
$$

The resulting solution is zero inflation for any date $t>0$ and an arbitrary initial condition $\pi_{t}$. The welfare function in a discretionary equilibrium is given by $W_{t}=-\pi_{t}^{2}$ and can be infinite if inflation is infinite.

We thus can make a comparable distinction between full credibility and limited credibility depending on the level of inflation on which private agents coordinate on in case of a policy deviation. If this level is infinite, then the Taylor rule is compatible with multiple equilibria. Otherwise, in the limited credibility case, the Taylor rule satisfying the Taylor principle is compatible with a unique subgame perfect equilibrium. 


\section{Conclusion}

In this paper, we connect two important concepts that were used to discuss the efficiency of monetary policy - credibility and determinacy. Limited credibility restricts the set of equilibria that can result from a given policy. Importantly, in the context of monetary policy, this restricts the set of equilibria to only bounded ones. In the context of Taylor rules, that means that the Taylor principle is both necessary and sufficient to ensure the existence of a single equilibrium. Yet, we show that limited credibility also allows for other equilibria where alternative policies are expected to be implemented. If, in general, there is no policy than ensure coordination on that policy whatever what private agents may expect, we derive conditions under which the central bank can still ensure coordination. 


\section{References}

Abreu, D. (1988): "On the Theory of Infinitely Repeated Games with Discounting," Econometrica, 56, 383-396.

Abreu, D., D. Pearce, and E. Stacchetti (1990): "Toward a Theory of Discounted Repeated Games with Imperfect Monitoring," Econometrica, 58, 1041-1063.

Adao, B., I. Correia, And P. Teles (2011): "Unique Monetary Equilibria with Interest Rate Rules," Review of Economic Dynamics, 14, 432-442.

Ascari, G. And A. M. Sbordone (2014): "The Macroeconomics of Trend Inflation," Journal of Economic Literature, 52, 679-739.

Atkeson, A., V. V. Chari, And P. J. Kehoe (2010): "Sophisticated Monetary Policies," The Quarterly Journal of Economics, 125, 47-89.

Barro, R. J. And D. B. Gordon (1983): "A Positive Theory of Monetary Policy in a Natural Rate Model," Journal of Political Economy, 91, 589-610.

Barthélemy, J. And E. Mengus (2018): "The signaling effect of raising inflation," Journal of Economic Theory, 178, 488-516.

Benhabib, J., S. Schmitt-Grohe, And M. Uribe (2001): "The Perils of Taylor Rules," Journal of Economic Theory, 96, 40-69.

Blanchard, O. J. And C. M. Kahn (1980): "The Solution of Linear Difference Models under Rational Expectations," Econometrica, 48, 1305-1311.

Bulow, J. And K. Rogoff (1989): "Sovereign Debt: Is to Forgive to Forget?" American Economic Review, 79, 43-50.

Campbell, J. R. And J. P. Weber (2018): "Discretion Rather than Rules: Equilibrium Uniqueness and Forward Guidance with Inconsistent Optimal Plans," Federal Reserve Bank of Chicago Working Paper, 4.

Challe, E. (2017): "Uninsured unemployment risk and optimal monetary policy," Mimeo.

Chang, R. (1998): "Credible Monetary Policy in an Infinite Horizon Model: Recursive Approaches," Journal of Economic Theory, 81, 431-461. 
Chari, V. V. And P. J. Kehoe (1990): "Sustainable Plans," Journal of Political Economy, $98,783-802$.

Christiano, L. And Y. Takahashi (2018): "Discouraging Deviant Behavior in Monetary Economics," NBER Working Papers 24949, National Bureau of Economic Research, Inc.

Clarida, R., J. Galí, and M. Gertler (2000): "Monetary Policy Rules and Macroeconomic Stability: Evidence and Some Theory," The Quarterly Journal of Economics, 115, 147-180.

Clarida, R., J. Gali, And M. Gertler (1999): "The Science of Monetary Policy: A New Keynesian Perspective," Journal of Economic Literature, 37, 1661-1707.

Cochrane, J. H. (2011): "Determinacy and Identification with Taylor Rules," Journal of Political Economy, 119, 565-615.

Debortoli, D., J. Kim, J. Lindé, And R. Nunes (forthcoming): "Designing a Simple Loss Function for Central Banks: Does a Dual Mandate Make Sense?" Economic Journal.

Eaton, J. And M. Gersovitz (1981): "Debt with Potential Repudiation: Theoretical and Empirical Analysis," Review of Economic Studies, 48, 289-309.

Eggertsson, G. B. And M. Woodford (2003): "The Zero Bound on Interest Rates and Optimal Monetary Policy," Brookings Papers on Economic Activity, 34, 139-235.

Gali, J. (2008): Monetary Policy, Inflation and the Business Cycle: An Introduction to the New Keynesian Framework, Princeton University Press.

Halac, M. And P. Yared (2017): "Fiscal Rules and Discretion under Self-Enforcement," NBER Working Papers 23919, National Bureau of Economic Research, Inc.

Hall, R. E. And R. Reis (2016): “Achieving Price Stability by Manipulating the Central Bank?s Payment on Reserves," NBER Working Papers 22761, National Bureau of Economic Research, Inc.

Ireland, P. N. (1997): "Sustainable monetary policies," Journal of Economic Dynamics and Control, 22, 87-108.

Kletzer, K. M. And B. D. Wright (2000): "Sovereign Debt as Intertemporal Barter," American Economic Review, 90, 621-639. 
Kurozumi, T. (2008): "Optimal sustainable monetary policy," Journal of Monetary Economics, 55, 1277-1289.

Leduc, S., K. Sill, And T. Stark (2007): "Self-fulfilling expectations and the inflation of the 1970s: Evidence from the Livingston Survey," Journal of Monetary economics, 54, $433-459$.

LeEper, E. M. (1991): "Equilibria under 'active' and 'passive' monetary and fiscal policies," Journal of Monetary Economics, 27, 129-147.

Loisel, O. (2008): "Central bank reputation in a forward-looking model," Journal of Economic Dynamics and Control, 32, 3718-3742.

(2009): "Bubble-free policy feedback rules," Journal of Economic Theory, 144, 15211559 .

Lubik, T. A. And F. Schorfheide (2004): "Testing for Indeterminacy: An Application to U.S. Monetary Policy," American Economic Review, 94, 190-217.

Nakata, T. (2018): "Reputation and Liquidity Traps," Review of Economic Dynamics, 28, $252-268$.

Nuno, G. And C. Thomas (2017): "Optimal Monetary Policy and Heterogeneous Agents," Mimeo.

Obstfeld, M. And K. Rogoff (1983): "Speculative Hyperinflations in Maximizing Models: Can We Rule Them Out?" Journal of Political Economy, 91, 675-687.

Phelan, C. And E. Stacchetti (2001): "Sequential Equilibria in a Ramsey Tax Model," Econometrica, 69, 1491-1518.

Rogoff, K. (1985): "The Optimal Degree of Commitment to an Intermediate Monetary Target," The Quarterly Journal of Economics, 100, 1169-89.

Sargent, T. J. And N. Wallace (1975): "'Rational" Expectations, the Optimal Monetary Instrument, and the Optimal Money Supply Rule," Journal of Political Economy, 83, 241254.

Sims, C. A. (1994): "A Simple Model for Study of the Determination of the Price Level and the Interaction of Monetary and Fiscal Policy," Economic Theory, 4, 381-399.

(2013): "Paper Money," American Economic Review, 103, 563-84. 
SunAKaWA, T. (2015): "A quantitative analysis of optimal sustainable monetary policies," Journal of Economic Dynamics and Control, 52, 119-135.

TAYLOR, J. B. (1993): "Discretion versus policy rules in practice," Carnegie-Rochester Conference Series on Public Policy, 39, 195-214.

(1999): Monetary Policy Rules, no. tayl99-1 in NBER Books, National Bureau of Economic Research, Inc.

Woodford, M. (1995): "Price-level determinacy without control of a monetary aggregate," Carnegie-Rochester Conference Series on Public Policy, 43, 1-46.

(2003): Interest and Prices: Foundations of a Theory of Monetary Policy, Princeton University Press. 


\section{Appendix: for online publication only}

Appendices A to E deal with extensions while Appendix F provide proofs of propositions.

\section{A Full credibility}

In this appendix, we characterize the set of equilibria when we allow for an unbounded punishment scheme and we then investigate the set of equilibria where the Taylor rule is followed.

\section{A.1 Characterizing the set of subgame perfect equilibria}

Let us first characterize the set of subgame perfect equilibria along the lines of Abreu (1988) and Chari and Kehoe (1990):

Lemma 13. The allocation $\left\{\pi_{t}, y_{t}, i_{t}\right\}_{t \geq 0}$ is the outcome of a subgame perfect equilibrium if and only if, for all date $t \geq 0$,

$$
W_{t}\left(\left\{\pi_{s}, y_{s}, i_{s}\right\}_{s \geq t}\right) \geq \max _{i}\left[U_{t}\left(\pi\left(\pi_{t+1}, y_{t+1}, i\right), y\left(\pi_{t+1}, y_{t+1}, i\right)\right)\right]+\beta \underline{\underline{W}},
$$

where $\underline{W}$ is the lowest welfare value of $W_{0}$ among all the allocations that are the outcome of an equilibrium.

This Lemma states that an allocation is the outcome of a subgame perfect equilibrium if the central bank has any incentives to pursue its policy rather than deviating to its best policy and then incurring the cost of the worst equilibrium. This constraint is sufficient because if this constraint is satisfied then a standard trigger strategy in which private expectations and the central bank revert to the worst equilibrium after a policy deviation leads to the outcome under consideration. This constraint is also a necessary condition because if this constraint is not satisfied, we can construct a policy that leads to a better outcome by allowing the central bank to do a one shot deviation as in Chari and Kehoe (1990).

Because whether an allocation is the outcome of a subgame perfect equilibrium or not depends on the lowest welfare value among all the allocations that are the outcome of an equilibrium, we now turn our focus on characterizing the worst equilibrium.

The worst equilibrium We now show that the lowest welfare value is $-\infty$ by constructing a subgame perfect equilibrium that attained this lowest value. We first show that we can construct such equilibria among the equilibria in which the central bank optimizes its policy at each date - discretionary equilibria. We then prove that the resulting allocations are the outcomes of subgame perfect equilibria.

At each period $t$, the central bank maximizes date-t welfare under the constraint of (NKPC) and (EE). This results into the following problem:

Problem 1 (Discretion).

$$
\max _{i_{t}} W_{t}
$$

under the constraints (NKPC) and (EE).

The first-order conditions of this problem lead to the optimal inflation-output gap trade-off:

$$
\kappa \pi_{t}+\lambda\left(y_{t}-y^{*}\right)=0
$$


First, the time-invariant solution of the Problem 1 is given by plugging equation (15) in (NKPC) and assuming that inflation and the output gap are constant. We call this solution the time-invariant discretionary allocation and we denote it by the couple $(\pi, y)$ defined as follows:

$$
\pi=\frac{\lambda \kappa}{\kappa^{2}+\lambda(1-\beta)} y^{*} \text { and } y=\frac{\lambda(1-\beta)}{\kappa^{2}+\lambda(1-\beta)} y^{*} .
$$

We can then express all the other solutions of the Problem $1\left(\pi_{t}, y_{t}\right)$ as a function of the time-invariant discretionary allocation:

$$
\pi_{t}-\pi=\frac{\lambda \beta}{\lambda+\kappa^{2}}\left(\pi_{t+1}-\pi\right) \text { and } y_{t}-y=-\frac{\kappa \beta}{\lambda+\kappa^{2}}\left(\pi_{t+1}-\pi\right) .
$$

Thus, Problem 1 admits a continuum of allocations that can be indexed by an arbitrary date-0 inflation $\pi_{0}:$

$$
\pi_{t}-\pi=\left(\frac{\lambda+\kappa^{2}}{\lambda \beta}\right)^{t}\left(\pi_{0}-\pi\right) \text { and } y_{t}-y=-\frac{\kappa}{\lambda}\left(\pi_{t}-\pi\right)
$$

In particular, note that the time-invariant discretionary allocation $(y, \pi)$ solves this equation for $\pi_{0}=\pi$. For each of this allocation, we can write the date-0 welfare function:

$$
W_{0}=-\left(1+\frac{\kappa^{2}}{\lambda}\right) \sum_{t=0}^{\infty} \beta^{t} \pi_{t}^{2}=-\left(1+\frac{\kappa^{2}}{\lambda}\right) \sum_{t=0}^{\infty} \beta^{t}\left[\left(\pi_{t}-\pi\right)^{2}+2 \pi\left(\pi_{t}-\pi\right)+\pi^{2}\right] .
$$

In the case of the time-invariant discretionary allocation, the welfare function $W^{D}$ is constant and bounded:

$$
W^{D} \equiv W_{0}=-\frac{1+\frac{\kappa^{2}}{\lambda}}{2(1-\beta)} \pi^{2}>-\infty
$$

When the weight on the output gap stabilization objective is non-zero $(\lambda>0)$, the other discretionary allocations - where the inflation paths diverge either toward $+\infty$ or $-\infty$ depending on the initial condition $\pi_{0}$ - all lead to an infinite loss. The first term of the sum in inequality (19) is a geometric series with a common ratio, $\frac{\left(\lambda+\kappa^{2}\right)^{2}}{\lambda^{2} \beta}$, strictly greater than 1 and hence this sum diverges to $-\infty$ and dominates the other terms.

Finally, let us note that the discretionary allocation is the outcome of a subgame perfect equilibrium, where the policy strategy $\sigma$ and the expectations rule $f$ are defined as follows:

$$
\begin{aligned}
& i_{t}=\sigma_{t}\left(\pi_{t+1}^{e}, y_{t+1}^{e}\right)=\alpha y_{t+1}^{e}+\left(1-\frac{\alpha \beta \kappa}{\lambda+\kappa^{2}}\right) \pi_{t+1}^{e}-\frac{\alpha \lambda y^{*}}{\lambda+\kappa^{2}}, \\
& f_{t}=\left\{\pi_{t+1}\left(\pi_{0}\right), y_{t+1}\left(\pi_{0}\right)\right\}
\end{aligned}
$$

where $\pi_{t+1}\left(\pi_{0}\right)$ and $y_{t+1}\left(\pi_{0}\right)$ are inflation and the output gap solutions to the discretionary problem given an initial inflation level $\pi_{0}$ defined in equations (18).

If private agents expect the discretionary allocation in the future (equation (22)), the central banker will optimally choose to stick to it by definition of Problem 1. This thus satisfies item (i) of definition 2. Private agents expectations are correct and they fulfill equations (NKPC) and (EE). Items (ii) and (iii) are thus also satisfied. The policy strategy $\sigma$ and the expectations rule $f$ forms a subgame perfect equilibrium.

We have found equilibria associated with an infinite loss, implying the following proposition:

Proposition 14. When $\lambda>0$, the worst subgame perfect equilibrium leads to an infinite loss: $\underline{W}=-\infty$.

Proof. Any discretionary allocation is the outcome of a subgame perfect equilibrium. These allocations are associated with an infinite loss as long as $\pi_{0} \neq 0$. Therefore, the worst sustainable equilibrium leads to an infinite loss as well, $\underline{W}=-\infty$. 
The set of subgame perfect equilibria Proposition 14 proves that inequality (14) is slack and does not restrict the set of subgame perfect equilibria. The central bank always prefers sticking to its policy strategy rather than deviating to a better policy because it would incur an infinite loss after such a decision. It is as if the central bank can commit to any policy strategy. Proposition 15 formalizes this result.

Proposition 15. When $\lambda>0$, any allocation is the outcome of a subgame perfect equilibrium.

When $\lambda=0$, the 0 -inflation allocation $\left(\pi_{t}=0\right.$ for all $\left.t\right)$ is the unique outcome of a subgame perfect equilibrium.

Proof. Case $\lambda>0$. It is a direct consequence of Proposition 14.

Case $\lambda=0$. In this case, the discretionary outcome leads to $\pi_{t}=0$ at each date 0 , which is the first-best allocation. Let us show that there are no other subgame perfect equilibria.

Let us consider an allocation that yields a different loss from 0 and let us assume that it is the outcome of a subgame perfect equilibrium. This implies that there exists a period $\tau$ where $\pi_{\tau} \neq 0$. Then, given the same private sector expectation, there exists a policy strategy that yields a strictly better outcome by setting inflation at 0 at every date, thus contradicting that the allocation is consistent with a subgame perfect equilibrium.

It is only when the central bank does not weight output gap stabilization $(\lambda=0)$ as Rogoff (1985)'s conservative central banker that the worst equilibrium yields a bounded loss. In this case, there is only one subgame perfect equilibrium that corresponds to the 0 -inflation allocation $\left(\pi_{t}=0\right.$ at each date $\left.\mathrm{t}\right)$. We now consider implications of Proposition 15 for Taylor rules.

\section{A.2 The set of of equilibria with the Taylor rule}

The fact that all allocations diverge except the 0 -inflation allocation however is insufficient to rule them out because they are all the outcome of a subgame perfect equilibrium since Proposition 15 proves that any allocation is an outcome of a subgame perfect equilibrium when $\lambda \neq 0$. Therefore, we can revisit the Taylor principle as follows:

Proposition 16. Suppose that the Taylor principle is satisfied $(\phi>1)$.

- If $\lambda>0$, then there exists multiple subgame perfect equilibria where the central bank follows the Taylor rule strategy $\left(\sigma^{T R}\right)$. These multiple equilibria correspond to different allocations.

- If $\lambda=0$, there exists a unique subgame perfect equilibrium where the central bank follows the Taylor rule. This equilibrium corresponds to the 0-inflation allocation.

Proof. We denote by $A(\phi)$ the 2-matrix that links current and expected variables when the central banker follows a Taylor rule:

$$
\left[\begin{array}{c}
E_{t} \pi_{t+1} \\
E_{t} y_{t+1}
\end{array}\right]=A(\phi)\left[\begin{array}{l}
\pi_{t} \\
y_{t}
\end{array}\right],
$$


where $A(\phi)$ is defined as follows:

$$
A(\phi)=\left[\begin{array}{cc}
1 / \beta & -\kappa / \beta \\
\phi / \sigma-1 /(\sigma \beta) & \kappa /(\sigma \beta)+1
\end{array}\right],
$$

When the central bank follows a Taylor rule satisfying the Taylor principle, the matrix $A(\phi)$ has two unstable eigenvalues. There exists a unique stable allocation $\pi_{t}=0$ and many unstable allocations that can be all expressed as a function of initial conditions $\left(y_{0}, \pi_{0}\right)$ (Woodford, 2003). All these allocations are subgame perfect if and only if $\lambda>0$ because of Proposition 15.

If $\lambda=0$, then the unique subgame perfect equilibrium coincides with the 0 -inflation allocation. This allocation does not contradict the Taylor rule in equilibrium; thus the unique subgame perfect equilibrium implemented by the Taylor rule corresponds to the 0-inflation allocation.

Following through on the Taylor rule is always credible even if it means blowing up the economy. The Taylor rule is thus consistent with many subgame perfect equilibria, even the ones that lead to diverging inflation paths and large social losses.

\section{B Following the Taylor rule in the short run?}

Following the Taylor rule satisfying the Taylor principle leads to a single equilibrium allocation. But, what about following such a rule only in the short run before switching to something else? Does it lead to another - different - equilibrium?

To investigate this situation, we consider a policy strategy in which the central bank follows the Taylor rule in the first $\tau \geq 0$ periods and, without loss of generality, switches to discretion at date $\tau+1$. Formally, we define such a policy strategy $\sigma^{[\tau]}$ as follows:

$$
\begin{aligned}
i_{t}=\sigma_{t}^{[\tau]}\left(h_{t}, \pi_{t+1}^{e}, y_{t+1}^{e}\right) & =\phi \pi_{t}=\phi \frac{\kappa y_{t+1}^{e}+(\beta+\kappa / \sigma) \pi_{t+1}^{e}}{1+\phi \kappa / \sigma} \text { for } t \leq \tau, \\
& =\sigma y_{t+1}^{e}+\left(1-\frac{\sigma \beta \kappa}{\lambda+\kappa^{2}}\right) \pi_{t+1}^{e}-\frac{\sigma \lambda y^{*}}{\lambda+\kappa^{2}} \text { for } t>\tau .
\end{aligned}
$$

The following Proposition describes the equilibrium outcome:

Proposition 17. There does not exist an LC-equilibrium where the policy strategy is $\sigma^{[\tau]}$ for a finite and positive number of periods $(\tau>0)$.

Proof. See Appendix F.2.

A LC-equilibrium exists only when either the Taylor rule is never followed $(\tau=0)$ or always followed $(\tau=\infty)$.

But why the Taylor rule cannot be implemented only in the short run? The problem is the switch to another policy and how it interacts with agents' rational expectations and the central bank's sequential rationality: agents anticipate the switch, thus modifying the central bank's incentives to switch earlier. As a result, by backward induction, the central bank never follows the Taylor rule. 
Cochrane (2011) argues that policy switch in the future in case of diverging inflation path does not prevent the equilibrium to exist. We instead argue that the threat to switch to more optimal monetary policy in case of diverging inflation path can prevent the formation of such a trajectory. Indeed, the expectations of a policy switch makes desirable to switch immediately, and therefore, if agents believe in the Taylor rule in the first place they should not coordinate on non-zero inflation trajectories.

\section{The 0-inflation allocation}

We assume the 0-inflation allocation to be the outcome of a LC-equilibrium.

The loss associated with the 0 -inflation allocation is $y^{*} /(1-\beta)$. This loss has to be compared with the loss under the best deviation plus the loss under the time-invariant discretionary allocation. As a result, the 0 -inflation allocation is the outcome of a LC-equilibrium if and only if the following condition is satisfied:

$$
\frac{1}{1-\beta} \leq \frac{\kappa^{2}}{\kappa^{2}+\lambda}+\kappa^{2} \frac{\beta}{1-\beta} \frac{\lambda+\kappa^{2}}{\left(\kappa^{2}+\lambda(1-\beta)\right)^{2}} .
$$

This condition is trivially satisfied when the weight on the output gap is $0(\lambda=0)$. If there is no inflationoutput gap trade-off, the central banker finds always desirable to fully stabilize inflation and the 0-inflation allocation is the outcome of a LC-equilibrium.

In the rest of the paper, we make the following assumption:

Assumption 2. Condition (SUST-TP) is satisfied.

Note that this corresponds to a range of intermediate values for the weight $\lambda$ that is put on the output gap stabilization objective or to a sufficiently high $\beta$ - as some form of Folk theorem would predict.

We make this assumption as we are not interested per se in the sustainability of the desired allocation but rather in the implementation of this allocation using a policy rule. For this former question, we refer the interested reader to the literature focusing on the sustainability of the desired allocation, which is usually the Ramsey allocation. ${ }^{18}$

Remark. Assumption 2 was not necessary in the context of subgame perfect equilibria in general, as all allocations are the outcome of a subgame perfect equilibrium.

\section{Flexible-price model}

As agents' behaviors can be function of past histories, the potential set of equilibria can include more equilibria than the time-consistent discretionary one, due to the possibility of trigger strategies as in Chari and Kehoe (1990), among others. Let us focus on the trigger strategy, where agents stick to a policy and then shift to the discretionary equilibrium if there was any deviation in the past. ${ }^{19}$

\footnotetext{
${ }^{18}$ For example, Kurozumi (2008) and Loisel (2008) have shown that, under plausible calibrations and using the time-invariant discretionary equilibrium as a punishment, the optimal allocation is subgame perfect in normal times and Nakata (2018) extended this result to the case of repeated liquidity traps and forward guidance.

${ }^{19}$ In general focusing on a particular trigger strategy is only a sufficient condition to be an equilibrium. This is also a necessary condition if the "punishment" equilibrium is the worst subgame perfect equilibrium (see Abreu et al., 1990).
} 
As a result, the central bank is better off not deviating at date $t$ from a particular policy leading to an inflation path $\left\{\pi_{k}\right\}_{k \geq t}$ when:

$$
\pi_{t}^{2}+\sum_{k>t} \beta^{k-t} \pi_{k}^{2} \leq \pi_{t}^{2}+\underbrace{\beta\left(\pi^{\prime}\right)^{2}}_{\text {Shift to discretion }} .
$$

The right hand side corresponds to the discounted sum of losses when deviating. When the agents expect to coordinate on a bounded level of inflation after a deviation $\left(\left|\pi^{\prime}\right|<\infty\right)$, the incentive constraint for not deviating from a policy leads date-t loss - the left hand term of inequality (27) - to be bounded as well. In contrast, when this level of inflation after a deviation is expected to be infinite $\left(\left|\pi^{\prime}\right|=\infty\right)$, the incentive constraint does not constraint the allocation so that any policy is subgame perfect.

Full credibility $\left(\pi^{\prime}=+\infty\right)$ As a benchmark, let us assume that private agents coordinate on the discretionary equilibrium characterized by an infinite level of inflation $\left(\pi^{\prime}=+\infty\right)$ followed by zero inflation. In this case, combining equations (12) and (13) yields the following condition:

$$
\phi \pi_{t}=E_{t} \pi_{t+1} .
$$

There is a large number of solutions to that equation in perfect foresight indexed by the date- 0 inflation rate $\pi_{0}:$

$$
\pi_{t}=\sum_{0 \leq k \leq t} \phi^{t-k} \delta_{k} .
$$

This means that multiple equilibria emerge from following a Taylor rule when this rule is always credible $\left(\pi^{\prime}=+\infty\right)$. In particular, the rule produces either zero inflation at any date or leads to diverging inflation paths when initial inflation is different from zero.

Limited credibility $\left(\left|\pi^{\prime}\right|<+\infty\right)$ We now suppose that private agents coordinate on a bounded equilibrium in case of a policy deviation. The credibility constraint (27) affects the implementation of a Taylor rule. Let us substitute in (27), the inflation path implied by following a Taylor rule:

$$
\left(\phi^{t} \pi_{0}\right)^{2}+\sum_{k>t} \beta^{k-t}\left(\phi^{k} \pi_{0}\right)^{2} \leq\left(\phi^{t} \pi_{0}\right)^{2}+\beta\left(\pi^{\prime}\right)^{2} .
$$

To start with, when initial inflation equals zero, $\pi_{0}=0$, this inequality boils down to $\left|\pi^{\prime}\right| \geq 0$ which is always satisfied. As a result, there exists an equilibrium in which the Taylor rule is followed at every date and in which inflation always equals 0 .

Can initial inflation differ from 0 ? In that case, the second left-hand-side member of equation (30) is as follows:

$$
\begin{aligned}
& \sum_{k>t} \beta^{k-t}\left(\phi^{k} \pi_{0}\right)^{2}=\infty, \text { if } \beta \phi^{2} \geq 1 \\
& \sum_{k>t} \beta^{k-t}\left(\phi^{k} \pi_{0}\right)^{2}=\frac{\beta \phi^{2 t+2}}{1-\beta \phi^{2}} \pi_{0}^{2}, \text { if } \beta \phi^{2}<1 .
\end{aligned}
$$

As a result, there are two situations to consider depending on the value of $\beta \phi^{2}$.

When $\beta \phi^{2} \geq 1$, equation (27) cannot be satisfied for any $t$. Thus, there does not exist an equilibrium in which the Taylor rule is followed and $\pi_{0} \neq 0$. 
When $\beta \phi^{2} \leq 1$, equation (27) may be satisfied at least in the short run. Yet, as time goes by and $t$ increases, inflation increases and the cost of continuing the Taylor rule diverges toward $+\infty$ which exceeds the second right-hand-side member of equation (27).

In the end, under limited credibility $\left(\left(\pi^{\prime}\right)^{2}<\infty\right)$, when $\pi_{0} \neq 0$ and under the Taylor rule, there always exists a date at which the central bank is better off deviating and, hence, the only equilibrium where the Taylor rule satisfying the Taylor principle is always followed is when the inflation rate is perfectly stabilized at date- 0 .

\section{E The Taylor rule in the absence of common knowledge}

We investigate in this appendix how our the results on the coordination of policy beliefs extend to the situation where agents cannot observe other agents' beliefs but only the macroeconomic outcomes.

More precisely, we assume that, when private agents form their expectations $f_{t}^{i}$, they do not observe other beliefs $P_{t}^{j}\left(., h_{t-1}\right)$ for $j \neq i$.

To start with, the following proposition extends Proposition 7 We show that, even in this case, the Taylor rule satisfying the Taylor principle can recoordinate dispersed policy beliefs as long as policy beliefs do not deviate too much from the Taylor rule:

\section{Proposition 18. (Without common knowledge)}

If the 0 -inflation allocation is sustainable (condition $X)$, then for any prior beliefs verifying $\int_{0}^{1} P_{-1}^{i}\left(\sigma^{T R}\right) d i>$ $\bar{\gamma}$ there exists a unique equilibrium allocation featuring $\pi_{0}>0$ and $\pi_{t}=0$ for any $t>0$. Furthermore $\pi_{0}$ decreases with average policy beliefs $\int_{0}^{1} P_{-1}^{i}\left(\sigma^{T R}\right) d i$.

Proof. See Proof of proposition 7 in Appendix F.6.

In the case of proposition 18, date-0 inflation is positive before reconverging to 0 in following periods. This implies that positive inflation in the case of Taylor rules and in the absence of shocks does not necessarily leads to hyperinflations - it simply reflects that all agents have not coordinated on the Taylor rule yet. In our setting, this coordination takes place in one period only as there are no information frictions. Any of such frictions are likely to make this coordination longer and so the deviations of inflation from its objective more costly. Of course, by making this coordination costlier, information frictions also reduce the incentive to stick to the Taylor rule and affects the level of $\bar{\gamma}$.

Adding information frictions To illustrate the quantitative impact of information friction on the coordination of policy beliefs, let us introduce sticky information by assuming that only a fraction of agents can revise their beliefs on the policy in each period. More precisely, we assume that, only a share of private agents $1 / N$ who expected the discretionary policy revise their beliefs when the central bank follows through on the Taylor rule. On the contrary, we assume that all agents revise their beliefs when observing the discretionary policy instead of the Taylor rule. In aggregate, it leads to an updating process $\gamma_{t+1}=\gamma_{t}+1 / N$ as long as $\gamma_{t}<1$ and private agents observe the implementation of the Taylor rule at date $t$. Otherwise, if they do not observe the Taylor rule they reset their beliefs to zero $\gamma_{t+1}=0$. The asymmetry in the learning process is supposed to capture the ability of private agents to punish the central bank to deviate from the Taylor rule in a setting in which the central bank promises to follow the rule but is not fully believed by the private sector. 
This hypothesis makes sure that the learning process is consistent with the LC-equilibrium definition. We initialize the prior beliefs to a fraction of $N, \gamma_{0}=i_{0} / N$, where $i_{0}$ is a positive integer smaller than $N$.

We calibrate the standard new-Keynesian model as in Eggertsson and Woodford (2003). ${ }^{20}$ We suppose that economic agents always fully discover the policy after $N=60$ periods at most and that they initially expect positive inflation close to its discretionary level, $i_{0}=5$ which corresponds to $\gamma_{0}=5 / 60$ ).

Figure 1 plots the dynamics of inflation and the output gap (thick blue curve) and private agents' expectations (red dotted curve). We plot these dynamics assuming that the central bank promises to stick to the Taylor rule and then stick to it only if it is optimal to do so.
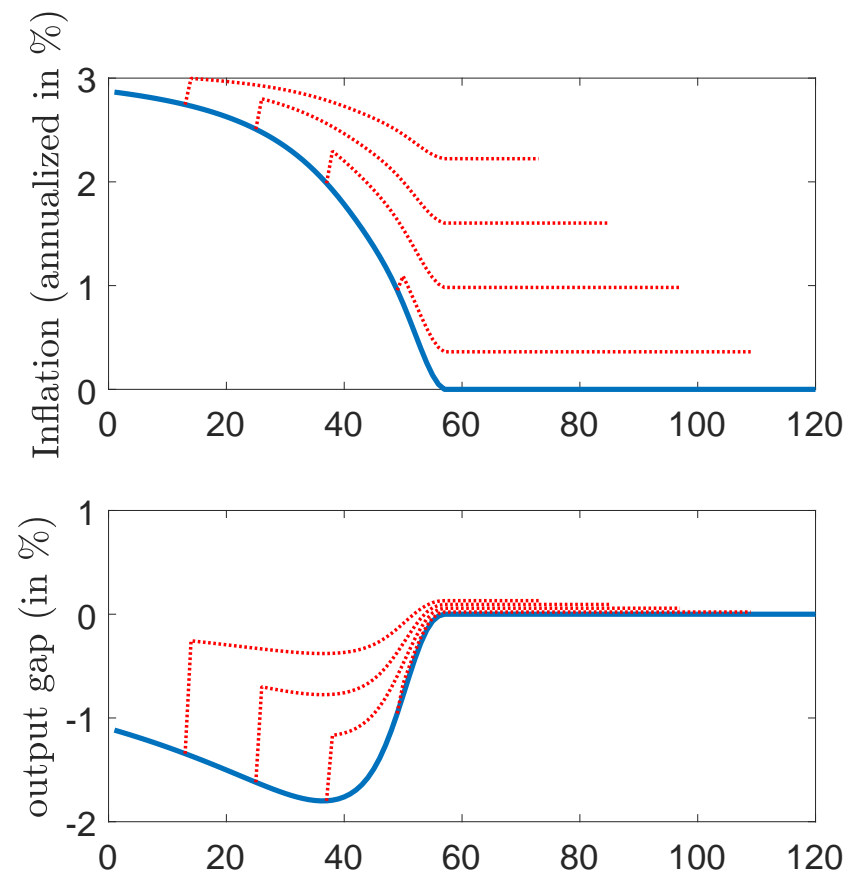

Figure 1: Inflation and the output gap dynamics and expectations with sticky information

Note: Blue curves plot the dynamics of inflation and the output gap when the central bank sets the interest rate following a Taylor rule satisfying the Taylor principle, while initially a share of agents anticipate discretion. Dotted red curves represent private agents expectations given their beliefs about future policies. Beliefs about future policy are updated sluggishly at the pace $1 / N$ where $N=60$. Initial beliefs are biased toward the discretionary policy, $\gamma_{0}=5 / 60$.

First, that sticky information does not necessarily prevent the reanchoring of expectations to the desired LC-equilibrium by the Taylor rule. Inflation and the output gap boith converge toward the 0-inflation allocation. Sticky information only slows down the reanchoring process that as, now, convergence takes time exactly $N-i_{0}=55$ periods, the convergence process being determined by the integer $N$.

Yet, when the learning process is too costly in relative terms with the long term gains of convincing private

\footnotetext{
${ }^{20}$ Parameters are calibrated as follows: $\kappa=0.02, \beta=0.99, \sigma=1, \lambda=\kappa / \theta$, where $\theta=8$, and $y^{*}=0.0625$.
} The policy parameter $\phi$ is calibrated to $\phi=1.5$. 
sector about the Taylor rule, the central bank may prefer not to reanchor expectations. For example, this happens(i) when private agents' expectations are far from the Taylor rule ( $\gamma$ close to 0 in our example) or (ii) when private agents learn slowly (large $N$ ) (iii) when the policy response to undesired departure from the desired equilibrium is costly to implement (for instance this is the case with strong response to inflation, $\phi$ or when the weight to the output gap stabilization objective is large).

Second, the Taylor principle leads inflation expectations to diverge, at least initially, before they reconverge to be consistent with the 0 -inflation equilibrium. This pattern results from two competing effects. First, the Taylor principle ensures that, for a given inflation expectation $E_{t} \pi_{t+1}$, the realized inflation, $\pi_{t}$, is lower thus leading inflation expectations to explode. Second, the learning process leads agents to revise downward their inflation expectations. As the learning process is not immediate, as in the previous paragraph, the first effect is not muted but it still ultimately disappears as agents progressively learn the policy that the central bank is actually following.

\section{F Proofs of Propositions}

\section{F.1 Proof of Proposition 1.}

Let assume that there exists a LC-equilibrium for which inflation is not bounded, i.e. for a certain date $\tau+1$ inflation $\pi_{\tau+1}$ is above a scalar $M>0$ that can be as large as we want. We now consider the sustainability condition at date $\tau$ :

$$
L_{\tau}>\pi_{\tau}^{2}+\lambda\left(y_{\tau}-y *\right)^{2}+\beta\left(\pi_{\tau+1}^{2}+\lambda\left(y_{\tau+1}-y *\right)^{2}\right),
$$

where $L_{\tau}$ is the social loss at period $\tau$ induced by the subgame perfect equilibrium with unbounded inflation path. On the right hand side of the inequality, the sum of the first two terms is greater than $U_{\tau}^{d}$, the loss given the best deviation at period $\tau$. Furthermore, since $\pi_{\tau+1}$ is very large the last two terms of the inequality may lead to a very high loss, and especially above the one generated by the time-invariant discretionary equilibrium. Thus $L_{\tau}>U_{\tau}^{d}+\beta W_{\tau+1}^{d}$. Finally, this proves that the unbounded inflation path is inconsistent with a LC-equilibrium. Notice that this proof does not depend on the policy $\sigma$ but only on the level of inflation, so the upper bound for inflation does not depend on $\sigma$.

\section{F.2 Proof of Proposition 3.}

First, let us note that the 0 -inflation allocation where $\pi_{t}=y_{t}=0$ at each date t satisfies (NKPC), (EE) and (TR). This allocation is also the outcome of a LC-equilibrium according to Assumption 2.

Now, consider another allocation consistent with (NKPC), (EE) and (TR). This means that there exists a date $t$ at which the inflation rate differs from 0 (there is no loss of generality to focus on $\pi_{t}$ as we can make the same reasoning with $y_{t}$ and note that either $\pi_{t}$ or $\pi_{t+1}$ should then differs from 0 ). We can easily rewrite all variables after this date as a product of the power of an unstable matrix times the level of inflation and output gap at time $t$ :

$$
\left[\begin{array}{c}
E_{t} \pi_{t+k} \\
E_{t} y_{t+k}
\end{array}\right]=A(\phi)^{k}\left[\begin{array}{c}
\pi_{t} \\
y_{t}
\end{array}\right],
$$


where $A(\phi)$ is the matrix defined in equation (24). As the Taylor principle is satisfied, all eigenvalues of $A(\phi)$ are greater than one, and therefore a non zero inflation level at time $t$ leads to diverging trajectory for the output gap and inflation. Proposition 1 show that all trajectories that lead to an infinite level of inflation are not the outcome of a LC-equilibrium. Thus all the allocations compatible with the Taylor rule but departing from the 0-inflation allocation are not the outcome of a LC-equilibrium.

\section{F.3 Proof of Proposition 4.}

The proof is very close to the proof F.1. Let consider a prior beliefs $\left\{P_{-1}^{i}\right\}$ on a common countable support $S(\Sigma)$. Suppose that at date t, an allocation features an inflation level $\pi_{t}>M$. Then, with the same reasoning that the one in the proof of Proposition 1, Appendix F.1, the constraint (SUST) is not satisfied if $M$ is sufficiently large. Besides, because the support of prior beliefs is on a common countable support, the date-t beliefs are also on a common countable support and hence there exists a policy move that is in the neighborhood of the best deviation policy that is not contained in the support of beliefs. Therefore the policymaker can deviate (with negligible cost compared to the best deviation) and the private agents recoordinate on the time-invariant discretionary equilibrium.

\section{F.4 Proof of Proposition 5.}

First, notice that when $y^{*}>0$ and $\lambda>0$, there exist at least two LCB-equilibria: the time-invariant discretionary equilibrium and the Taylor rule satisfying the Taylor principle and expectations consistent with the 0 -inflation allocation with prior beliefs affecting a mass probability on the policy. The interest rate differs in the two resulting allocations at any date $t \geq 0$. Therefore whatever the strategy profile $\sigma$ we can always find prior beliefs such that the resulting equilibrium allocation features an interest rate that differs from $\sigma_{t}\left(h_{t-1}\right)$. To see that it suffices to pick one of the two LCB equilibria described above.

\section{F.5 Proof of Proposition 6 .}

Let $\sigma \in \Sigma$ be a policy strategy profile leading to determinacy in the context of LC-equilibrium. We denote by $(\sigma, f)$ the unique LC-equilibrium consistent with $\sigma$. Let suppose that the prior beliefs belong to a common finite support including the policy strategy $\sigma$.

First, the policymakers can either choose the best policy at date 0 or choose one of the policies expected by private agents. Indeed, choosing another policy is dominated by the best policy because the continuation value for the policymaker is the same and the current social welfare is higher when choosing the best policy.

Given prior beliefs $\left\{P_{-1}^{i}\right\}_{i \in(0,1)}$, private agents can infer the corresponding inflation and output gap expectations $\left(\pi_{1}^{e}, y_{1}^{e}\right)$ as the average of inflation and output gap weighted by prior probabilities. If we denote by $\gamma$ the average weight put on policy $\sigma, \int_{0}^{1} P_{-1}^{i}(\sigma)=\gamma$, then $\left|\pi_{1}^{e}-\pi_{1}(\sigma)\right| \leq(1-\gamma)\left(2 M+\left|\pi_{1}(\sigma)\right|\right)$, where $\pi_{1}(\sigma)$ is date- 1 inflation in the unique equilibrium allocation resulting from $\sigma$ and $M$ is the supremum of inflation in all equilibrium allocations. We can do the same for output gap expectations.

Because the inequality (7) is strict and by continuity, the inequality (7) where we replace $\pi_{1}=\pi_{1}^{e}, y_{1}=y_{1}^{e}$ and $i_{1}=\sigma_{1}\left(\pi_{1}^{e}, y_{1}^{e}\right)$ is satisfied for any $\sigma^{\prime}$ in the support of beliefs, for $\gamma$ sufficiently close to 1 . Continuity of $\sigma_{1}$ with respect to the two arguments is required for the reasoning. 


\section{F.6 Proof of Proposition 7.}

First, Assumption 2 and proposition 6 proves that there exists a threshold $\bar{\gamma}$ such that if prior beliefs put on the Taylor rule strategy $\sigma^{T R}$ is higher than $\bar{\gamma}$ then the unique equilibrium allocation is the 0 -inflation allocation. If this threshold is non-zero, then this threshold is defined by:

$$
W_{0}\left(\left\{\pi_{t}, y_{t}, i_{t}\right\}_{t \geq 0}\right)>\max _{i} U_{0}\left(\pi\left(\pi_{1}, y_{1}, i\right), y\left(\pi_{1}, y_{1}, i\right)\right)+\beta W^{D}
$$

All the terms being quadratic in $y^{*}, \bar{\gamma}$ does not depend on $y^{*}$.

\section{F.7 Proof of Proposition 8 .}

We now suppose that monetary policy faces a lower bound: $i_{t} \geq-\bar{i}$, with $\bar{i}>0$. The permanent liquidity trap is a pair of steady-state output gap and inflation $(y, \pi)$ solving the following model:

$$
\pi_{t}=\beta E_{t} \pi_{t+1}+\kappa y_{t} \text { and } y_{t}=E_{t} y_{t+1}-\frac{1}{\sigma}\left(-\bar{i}-E_{t} \pi_{t+1}\right)
$$

The resulting per period loss is:

$$
\bar{i}^{2}+\left(\frac{1-\beta}{\kappa} \bar{i}+y^{*}\right)^{2}<\infty .
$$

As this loss is constant over time, the total welfare loss in a permanent liquidity trap is also bounded:

$$
\frac{1}{1-\beta}\left(\bar{i}^{2}+\left(\frac{1-\beta}{\kappa} \bar{i}+y^{*}\right)^{2}\right)<\infty .
$$

\section{F.8 Proof of Proposition 9.}

Let suppose that the Taylor rule is always satisfied. Then, following previous subsection, we can write the model as follows:

$$
\left[\begin{array}{c}
E_{t} \pi_{t+1} \\
E_{t} y_{t+1}
\end{array}\right]=A(\phi)\left[\begin{array}{l}
\pi_{t} \\
y_{t}
\end{array}\right] .
$$

When the Taylor principle is not verified there is one eigenvalue lower than one and one above one, we call them $\lambda_{1}<0$ (associated with the vector $V_{1}$ ) and $\lambda_{2}>0$ (associated with the vector $V_{2}$ ) respectively. We thus can decompose $\left[\begin{array}{ll}\pi_{t} & y_{t}\end{array}\right]^{\prime}=V_{1} w_{1, t}+V_{2} w_{2, t}$ where:

$$
E_{t} w_{i, t+1}=\lambda_{i} w_{i, t} .
$$

Therefore, using the argument developed in the proof F.2, we see that to be a LC-equilibrium one might impose $w_{2, t}=0$. Therefore, all the LC-equilibria consistent with a Taylor rule which does not satisfy the Taylor principle satisfy:

$$
\left[\begin{array}{ll}
\pi_{t} & y_{t}
\end{array}\right]^{\prime}=V_{1} w_{1, t}, \text { where } w_{1, t+1}=\lambda_{1} w_{1, t} .
$$

We can index each equilibrium by the initial (arbitrary) condition $\pi_{0}=V_{11} \pi_{0}$, where $V_{11}$ is the first member of the column vector $V_{1}$. Thus,

$$
\pi_{t}=\lambda^{t} \pi_{0}
$$


In addition, since $y_{t}=V_{12} w_{1, t}=V_{12} \lambda_{1}^{t} w_{1,0}=\frac{V_{12}}{V_{11}} \lambda_{1}^{t} \pi_{0}$, i.e.

$$
y_{t}=\lambda^{t} \omega \pi_{0}, \text { with } \omega=\frac{V_{12}}{V_{11}} .
$$

However, such an allocation is the outcome of a LC-equilibrium if and only if the initial condition $\pi_{0}$ is not too large (see Proposition 1).

The role of the inflation bias. Let suppose that the initial level of inflation is $\pi_{0}$ and the level of output gap is $y_{0}=\frac{V_{12}}{V_{11}} \pi_{0}$. This is a situation in which the economy converges to the 0-inflation allocation. The maximal and minimal values for inflation correspond to levels of inflation such that the sustainability constraint (equation (SUST)) is exactly binding.

$$
\sum_{t=0}^{\infty} \beta^{t}\left[\pi_{t}^{2}+\lambda\left(y_{t}-y^{*}\right)^{2}\right]=\left[\frac{\lambda \kappa}{\lambda+\kappa^{2}} y^{*}+\frac{\lambda \beta}{\lambda+\kappa^{2}} \pi_{1}\right]^{2}+\lambda\left[\frac{\lambda}{\lambda+\kappa^{2}} y^{*}-\frac{\kappa \beta}{\lambda+\kappa^{2}} \pi_{1}-y^{*}\right]^{2}+\frac{\beta}{1-\beta} W^{d}
$$

where $W^{d}$ denotes the loss under discretion. One can replace $\pi_{t}=\lambda_{1}^{t} \pi_{0}$ in this expression and find a quadratic equation in $y^{*}$ and $\pi_{0}$ :

$$
a \pi_{0}^{2}+b \pi_{0} y^{*}+c y^{* 2}=0
$$

If the inflation bias is absent, then $\pi_{0}$ is necessarily zero as well and the minimum and maximum levels of inflation are zero as well. Otherwise, we can divide this quadratic equation by $y^{* 2}$ and we find a quadratic polynomial in $\pi_{0} / y^{*}$. First, Assumption 2 guarantees that if $\pi_{0}$ is zero the path is subgame perfect, this translates into $c<0$. Second, after some computations we can prove that $a$ is always positive (this is consistent with Proposition 1 that shows that inflation is always bounded in a subgame perfect equilibrium). Indeed, coefficient $a$ is as follows:

$$
a=\frac{1}{1-\beta \lambda_{1}^{2}}\left[1+\lambda\left(\frac{V_{12}}{V_{11}}\right)^{2}\right]-\lambda_{1}^{2} \lambda \beta
$$

which is positive. Thus, $\pi_{0} / y^{*}$ satisfies a quadratic polynomial which is negative in 0 and tends to $+\infty$ for very large and negative values. The quadratic polynomial has two roots of opposite signs that we denote by $x_{1}<0$ and $x_{2}>0$. Consequently, the lower and upper bounds $(\underline{\pi}$ and $\bar{\pi})$ satisfy:

$$
\underline{\pi}=x_{1} y^{*} \text { and } \bar{\pi}=x_{2} y^{*}
$$

Therefore, the upper and the lower bounds for inflation are directly proportional to the inflation bias.

\section{F.9 Proof of Proposition 10.}

Let first show that if shocks are bounded, inflation is bounded in any LC-equilibrium. Suppose that there exists an allocation with a very large level of inflation at date $t$. This high level of inflation is either associated with a high output gap or high inflation expectations. 
First case: high inflation expectations. Since the shocks are bounded, the loss under the timeinvariant discretionary allocation is bounded as well. If inflation expectations are really high they thus imply a loss that dominates the loss under the time-invariant discretionary allocation which is impossible since it is the worst LC-equilibrium.

Second case: high output gap and low inflation expectations. If inflation expectations are low, the best deviation policy triggers a mild loss while the current loss is very high; the central banker has thus any incentives to deviate (even if the continuation value of the loss is zero).

In the two cases, the allocation with unbounded inflation path is not the outcome of a LC-equilibrium.

We now deal with the AR(1) with L-2 innovations shocks. It is easy to see that under this assumption the loss under the time-invariant discretionary policy is bounded. Therefore, we can apply the exact same reasoning than before.

\section{F.10 Proof of Proposition 11.}

Because shocks are i.i.d. and zero mean expected inflation and output gap are zero if the central bank follows a Taylor rule forever. Consequently, we get

$$
\begin{aligned}
\pi_{t}^{T R} & =\frac{1}{1+\alpha \kappa / \sigma}\left(u_{t}-\kappa / \sigma\left(\epsilon_{t}-r_{t}^{n}\right)\right), \\
y_{t}^{T R} & =\frac{1}{1+\alpha \kappa / \sigma}\left(-\alpha / \sigma u_{t}-1 / \sigma\left(\epsilon_{t}-r_{t}^{n}\right)\right) .
\end{aligned}
$$

While inflation and the output gap under the best deviation policy are:

$$
\begin{aligned}
\pi_{t}^{B D} & =\frac{\lambda \kappa}{\kappa^{2}+\lambda}\left(y^{*}+u_{t} / \kappa\right), \\
y_{t}^{B D}-y^{*} & =-\kappa / \sigma \pi_{t} .
\end{aligned}
$$

Furthermore, an allocation implemented by the Taylor rule is a LC-equilibrium if and only if:

$$
\left[\pi_{t}^{T R}\right]^{2}+\lambda\left(y_{t}^{T R}-y^{*}\right)^{2}+\beta L^{T R} \leq\left[\pi_{t}^{B D}\right]^{2}+\lambda\left(y_{t}^{B D}-y^{*}\right)^{2}+\beta L^{B D},
$$

where $L^{T R}$ and $L^{B D}$ are the losses associated with the allocation implemented by the Taylor rule policy while and the time-invariant discretionary equilibrium respectively. Since shocks are i.i.d. these losses are independent of realized shocks at date $t$.

Finally to prove Proposition 11, we simply need to prove that (44) is verified for small shocks. This can be proved by continuity. When the variance of shocks tends to zero and the size of the current shock tends to zero as well this inequality converges toward the inequality ensuring that the 0-inflation allocation is a LC-equilibrium.

One can remark that as if we suppose small variance of shocks, then this inequality is violated as soon as one of the three shocks is too large. For the monetary policy shock and the natural rate of interest shock this is trivial since the right-hand-side of the inequality is unaffected by these shocks while the right-hand-side first two members increase with the size of these shocks. For the cost-push shock, one can use a Taylor expansion to show that the left-hand-side members diverge more quickly than the right-hand-side toward $+\infty$. 


\section{F.11 Proof of Proposition 12.}

When the monetary policy shock is zero, equations (NKPC) and (EE) are modified as follows:

$$
\begin{aligned}
& \pi_{t}=\beta(1-p) \pi_{t+1}+\beta p \bar{\pi}^{D}+\kappa y_{t}, \\
& y_{t}=(1-p) y_{t+1}+(1-p) \bar{y}^{D}-1 / \sigma\left(\phi \pi_{t}-(1-p) \pi_{t+1}-p \bar{\pi}^{D}\right),
\end{aligned}
$$

where variables $\pi_{t}$ and $y_{t}$ denote the sequence of inflation and the output gap in the absence of shocks at date $t$, scalars $\bar{\pi}^{D}$ and $\bar{y}^{D}$ denote the average inflation and output-gap in the discretionary allocation in case of non-zero monetary policy shock.

We can remark that all forward-looking variables are multiplied by $(1-p)$ so all the eigenvalues of the dynamic system are multiplied by $(1-p)$. The dynamic system is unstable if and only if the lowest eigenvalue is largest than 1 thus the economy diverges for any non-zero initial conditions (absent of shocks) if and only if $\phi>1-p$.

In addition, the unique stable solution is given by:

$$
\left[\begin{array}{c}
\pi_{t} \\
y_{t}
\end{array}\right]=[I-A(1-p)]^{-1} A p\left[\begin{array}{c}
\kappa \\
1
\end{array}\right] \frac{\lambda y^{*}}{\lambda+\kappa^{2}}
$$

We can observe that an increase in the probability of large shock increases inflation and the output gap (even in absence of shocks) through private agents' expectations. It also reduces long-term gains to follow the Taylor rule because the probability of following it decreases with $p$.

Therefore, there exists a probability $\bar{p}$ such that following a Taylor rule -even in the absence of contemporaneous shock- is always suboptimal. The central banker never follows the Taylor rule when the probability $p$ is above this threshold.

The higher the probability of a large shock, the less incentives the central banker has to stick to the Taylor rule. There exists a thresholds, $\bar{p}$, such that when the probability of large shocks is above the threshold $\bar{p}$, the central banker never follows the Taylor rule. There are two reasons: first, inflation and the output gap are closer and closer to the discretionary allocation when $p$ increases, second the long-term gains of the Taylor rule decreases with $p$ (it is as if the discount factor of the central banker is lower). 